\title{
Big Data Applications in Healthcare Administration
}

Joseph E. Kasten, Pennsylvania State University, York, USA

\begin{abstract}
The healthcare industry has a growing record of using big data-related technologies such as data analytics, internet of things, and machine learning, especially in the clinical areas. However, healthcare institutions must also perform all of the administrative processes just as any other organization. Thus, like many other industries, healthcare has begun to apply these same technologies to improve their understanding of these internal operations and use them to make better decisions and run a more effective operation. This study takes a structured literature review approach to describe the current state of this literature and identify the major themes and priorities of both the research community and the healthcare industry as a whole. The contribution made by this study is to provide a comprehensive analysis of the state of the literature to use as a foundation for the future research opportunities noted in the paper.
\end{abstract}

\section{KEYWORDS}

Administration, Big Data, Healthcare, Structured Literature Review

\section{INTRODUCTION}

As the concept of big data and the tools that surround it have matured, the world of business has witnessed an inexorable migration of these tools from the financial sector to other areas of commerce such as transportation and insurance. Shortly into this transition, these tools made their way to the healthcare industry. Some of the first areas within healthcare that big data techniques first appeared were in the clinical areas such as oncology, radiology, and genetics (Chang \& Choi, 2016). However, healthcare organizations are also businesses with the same internal and external processes as any other business. These include the hiring of staff, the procuring of supplies, and the running of sometimes vast physical plant installations. So, it is not surprising that the healthcare industry has begun using big data techniques to improve their ability to perform these important, yet often out of the spotlight, activities.

There is a large and enthusiastic literature surrounding the clinical uses of big data in healthcare and there have been a number of reviews in these various areas (Pashazadeh \& Navimpour, 2018; Otokiti, 2019). However, there is a much smaller, but still important, literature that describes the uses of big data in the administration of healthcare and hospital activities. The purpose of this paper is to review the literature regarding the uses of big data and its ancillary tools and processes in the 
improvement of healthcare processes. The term improvement can, of course, encompass many different aspects of healthcare and hospital administration. Improvement can involve the reduction of costs, the improvement of patient care and experience, the prediction of patient admission or readmission, and the allocation and management of hospital resources. In these and many other cases the use of big data techniques and tools has provided many options and opportunities for hospitals, healthcare systems, and other parts of the overall healthcare industry to create more effective and efficient methods for providing quality healthcare to their community and the nation.

\section{BACKGROUND}

When most people encounter the healthcare industry, they see mostly the clinical side of the process (except when it comes time to pay the bill). Many do not consider that healthcare is an industry and even if the facility they are using for provision of healthcare services is a non-profit organization, the business side of the healthcare equation is a crucial part of the overall system. Hospitals depend on well-trained and experienced personnel to perform their essential services, thus human resources is a critical activity. Even if they do not have shareholders to answer to, though many healthcare systems in the US are publicly traded companies, they still must monitor costs and revenues just as any other organization and therefore the financial processes of the organization is just as important as for any Fortune 500 firm. Issues of workflow streamlining, document management, and technology selection and implementation have very important roles in healthcare just as they do in any other organization.

\section{Healthcare as a Business}

Healthcare organizations face many of the same challenges as other firms. Cost reduction is a constant process. Large healthcare bureaucracies are inherently expensive to run, and with the high level of expertise in the clinical side of the organization and very expensive equipment to purchase and operate, cost reduction processes often take center stage. This is vitally important not just for the success of the enterprise, but for the healthcare system writ large. Workflow analysis allows the reduction of delays for patients to receive care and also reduce the overall complexity of the organization (Wolf, Herrmann \& Rothermel, 2013). Increasing accuracy is a fundamental objective of healthcare administration as it is closely related to not just patient outcomes, but also the areas of cost reduction, asset utilization, and continuous process improvement (Cutler, Wikler \& Basch, 2012).

\section{Big Data Related Technologies}

When organizations say they are using "big data," it also means they are using some other tools to utilize that large collection of data. The simple collection of data, even in large amounts, is of little value unless actionable information can be extracted from them. Therefore, when reviewing the literature on the use of big data in the administration arm of healthcare, these ancillary but closely related technologies and tools must be included in the analysis. In the current study, the search for literature of big data in healthcare administration was combined with the following technologies to provide a more robust view of the literature:

- Internet of Things (IoT): The proliferation of sensors attached to machines, monitoring a process, and even measuring a patient's vital signs, is the basis of much of the huge datasets that organizations are using to create new understandings of their processes. Therefore, even if big data is not explicitly mentioned, they are implicitly creating a big data environment;

- Deep Learning: A branch of machine learning that leads to tools such as Artificial Neural Networks (ANN) that can be trained to make decisions such as classifications or speech recognition. Related to big data because the datasets required to train and verify the algorithms are typically very large and commonly fall into the general definition of big data; 
- Machine Learning: A broader category of algorithms that use training data to create the ability to make decisions. Included in this are many different types of training methods and architectures, which are out of the scope of this paper but can be reviewed in (ref);

- Data Analytics: A broad term covering all of the statistical and mathematical tools and techniques commonly used to analyze and draw meaningful information from big data repositories.

There are, of course, many other terms that can be associated with big data - based technologies, but these terms are some of the more commonly used and therefore make a good starting point for the literature examination process. In the rest of the paper, this grouping of technologies and tools will be referred to as Big Data technologies.

\section{METHODOLOGY}

As this study is a structured review of the literature, it is important that the methodology used is both transparent and easily replicated. Briner \& Denyer (2012) provide an easily implemented and repeatable approach to the completion of a systematic literature review:

- Identify the research question(s);

- Locate and select relevant studies;

- Critically appraise the studies;

- Analyze and synthesize the findings;

- Disseminate the findings.

There are two research questions driving this study:

- For which healthcare administrative processes are big data technologies (as defined in this study) being used to improve or analyze?

- For how long have big data technologies been used to improve or analyze healthcare administrative processes?

In order to perform a structured literature review properly, a set of ground rules must be established to ensure consistency and validity of the study protocol. This study limits the review to peer reviewed academic journals, conference proceedings, dissertations, and edited book chapters. This removes the professional journals, unpublished papers, white papers, and other sources of information from the study. This is not to say that they are not sources of valid information, only that the study is centered on the research efforts that have resulted in either specific tools to be used in healthcare administration tasks or big data tools that are being used to research these activities. Future research will be necessary to unearth whether the directions of researchers are aligned with the concerns and ideas of the practitioner literature.

Searches were carried out in many of the major electronic databases that provide coverage for the vast majority of scholarly journals in the field. The databases analyzed were ABI/Informs, Emerald, IEEE Explore, JSTOR, Science Direct, Scopus, Springer, Taylor \& Francis, Web of Science, Google Scholar, PubMed, CINAHL, and ACM. The searches were conducted by searching the metadata (title, abstract, keywords) using the following search terms in all combinations: big data, Internet of Things (IoT), deep learning, machine learning, and analytics along with healthcare and hospital. To center on the administrative aspects of the industry, administration and management were also included. This study does not claim to be exhaustive, but the wide selection of databases combined with the increased rate of result duplication as the study progressed, provides evidence that a reasonable 
coverage of the topic has been achieved. There was no temporal restriction placed upon the searches so that the full scope of relevant research might be discovered.

This search protocol retrieved thousands of initial results, but the vast majority of them were focused on the clinical side of the healthcare industry. This is partially because of the use of the search term management (i.e. "disease management"), partially because of the automatic use of synonyms in many search protocols, and probably because the exclusion of purely clinical systems is very difficult to do in many situations. In the case of many of these returned articles, the title was sufficient to classify them as clinical in nature. However, that still left a list of over a thousand articles to deal with. After reading the abstract of these articles to gain more insight into their core topic, the final list of 227 articles remained to begin the actual analysis.

For those papers accepted into the study, the next step was to use the abstract, introduction, and conclusion sections to gain a more complete understanding of the topic being addressed by the author(s). Using a technique known as open coding, which is a qualitative research method of identifying the set of concepts within a document, the papers were sorted into sets of major themes that represent the focus of the author(s). As these themes were defined and refined, it became apparent that the complexity of the topics being studied required a more subtle approach. Therefore, a set of sub-themes were developed under the major topic headings to provide a better understanding of the scope of the research being undertaken. As these themes and sub-themes took shape, the last task was to categorize each paper into the theme and sub-theme that fit them most accurately. It should be noted that a significant number of studies could have been slotted into multiple categories. These papers required a deeper analysis to discern their main contribution. This involved a close reading of the entire paper, not just the introductory and concluding sections, to make that determination based on the author's stated goals, outcomes, and methodologies. The interdisciplinarity inherent in the healthcare and many other industries makes this overlap unavoidable.

To complete the structured review protocol, the findings of the literature analysis are presented and discussed in the following section. The complete literature review process followed in this project is depicted in Figure 1.

\section{Figure 1. Literature review process}

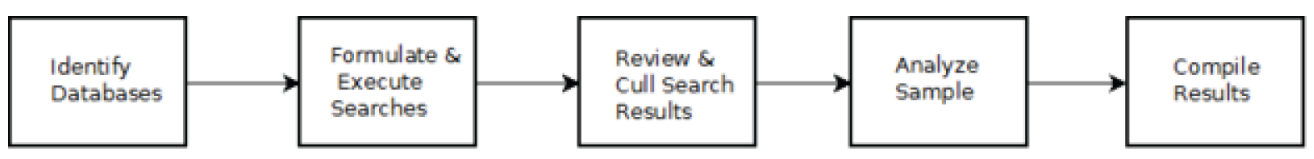

\section{RESULTS}

The findings section is divided into two sections. The first contains an overview of the descriptive statistics of the sample. The second section describes the various research themes and sub-themes contained in the sample.

\section{Descriptive Statistics}

The documents included in this study come from only three sources: journals, conference proceedings, and book chapters. The searches did not uncover any theses, dissertations, or books on the topics listed in the methodology section. The breakdown among these three forms is shown in Table 1.

The proportions of each format given above held relatively constant for each of the themes discussed below except for the technology theme, which had almost twice as many conference proceedings as journal articles. Most of these articles discussed a framework or architecture for 
Table 1. Types and quantity of article types uncovered in the literature review

\begin{tabular}{|l|l|}
\hline \multicolumn{1}{|c|}{ Article Type } & \multicolumn{1}{c|}{ Quantity Found } \\
\hline Journal Articles & 121 \\
\hline Conference Proceedings & 94 \\
\hline Book Chapters & 12 \\
\hline
\end{tabular}

a proposed system or tool, which is a common topic at many technology-related conferences and workshops.

There were no time boundaries placed upon the searches so that the full range of activity in the field could be captured. The searches were all completed by May 1, 2020 and the temporal results of those searches are shown in Figure 2. The search results show that there were very few articles published on Big Data - type processes or tools in healthcare administration prior to 2014, with the earliest occurring in 2007. However, in 2014 the level of activity began to increase significantly with an exponential growth displayed through 2019. Since the data for 2020 represents only a third of the year, it appears that the trajectory points to at least as many publications in the field for the current year.

\section{Research Themes}

There are four research themes identified in the literature: resource management, technology, hospital management, and patient outcomes. These themes are expanded on in the following paragraphs. However, within each theme there are sub-themes that serve to better focus the analysis of the papers within each theme. To assist in understanding how these various sub-themes organize to support the major themes, Figure 3 provides a graphical representation of these themes and sub-themes.

Figure 2. Number of publications in Big Data / Healthcare administration by year (as of 1 May, 2020)

\section{Healthcare Administration / Big Data Publications by Year}

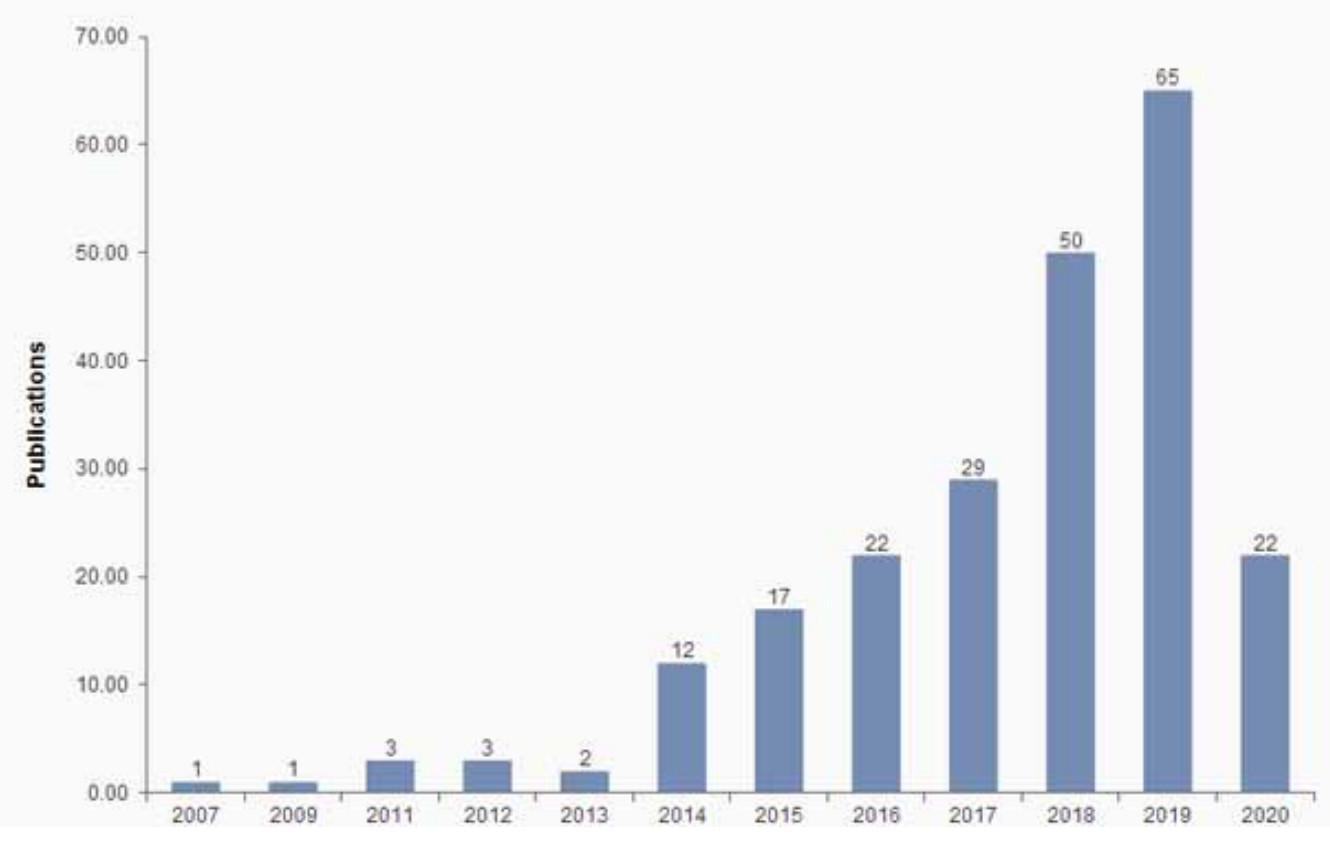


Figure 3. Breakdown of themes and sub-themes within the Big Data/Healthcare Administration Literature

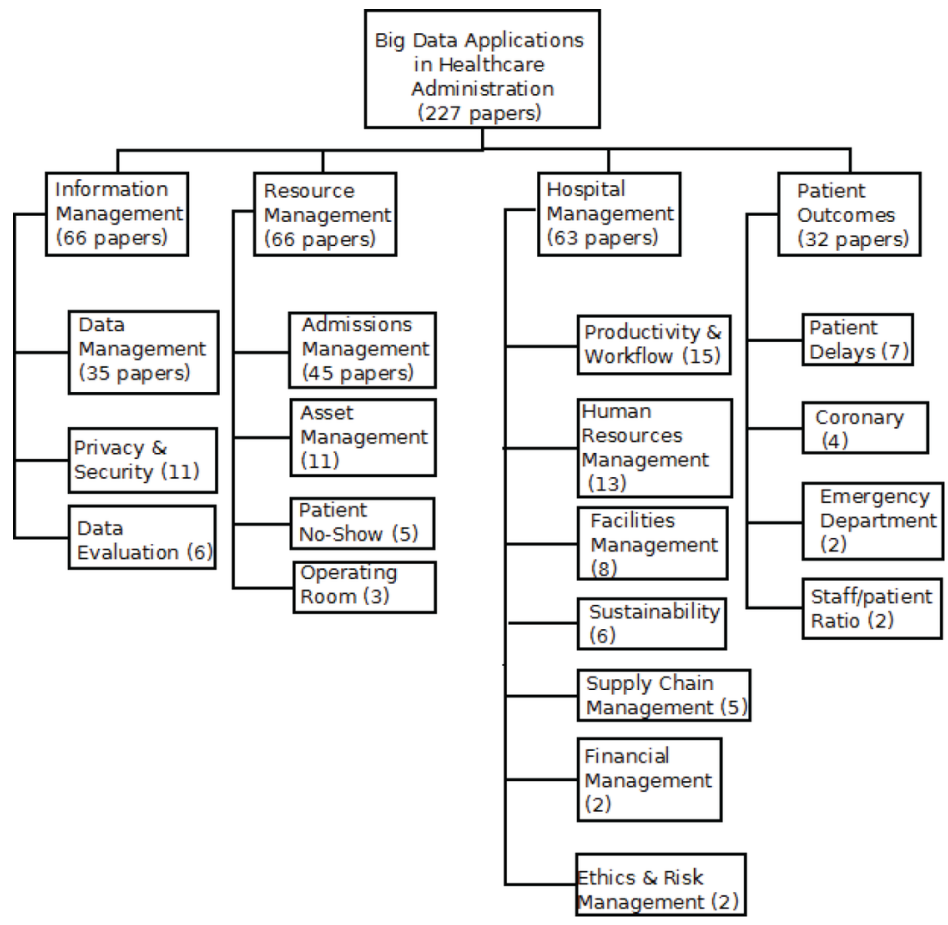

Three of the four themes identified in this analysis are of very similar size, which suggests an even spread of importance for these various topics. The Information Management theme will be discussed first. The papers that fall into this theme are centered on the use of Big Data technologies to assist in the handling and application of organizational data and information to improve, or in some cases enable, certain functions. As will be true of most of these research themes, a number of authors provide very important overview papers that help to orient those readers who are relatively new to the topic. Such overviews can be found in Robinson, Presskila \& Lawrence (2020) who discuss the Internet of Things, Alsinglawi \& Mubin (2019) who explore predictive analytics and deep learning, and Menasalvas, Rodriguez-González \& Gonzalo (2018) who look into the mining of electronic health records.

Of the three sub-themes in this grouping, by far the largest is that of data management (35 papers). These authors develop mechanisms and tools that use Big Data technologies to improve the movement and analysis of healthcare information. Some examples of these efforts include the team of Redfield et al (2020) who develop a machine learning record linkage mechanism to improve information flow between emergency services and the emergency department and Mehmood, Mehmood \& Song (2019) who look at the use of IoT mechanisms to improve e-prescription processes. Perdana et al (2019) link Big Data with knowledge management tools to increase the efficiency of hospital inpatient services and Silvestri et al. (2019) describe a Big Data architecture that improves the extraction of actionable information from Electronic Health Records (EHR).

The privacy and security of patient and hospital data is of prime importance and eleven author teams addressed this imperative. Some excellent examples of these efforts include Xu et al's (2019) design of a blockchain-based privacy preserving mechanism for large health data depositories, Martinez's (2018) approach to securing IoT-based medical device systems, and Yoon-Su and SeungSoo (2019) who consider virtual reality to help professionals secure multimedia healthcare information. 
The last sub-theme (6 papers) includes those papers using Big Data technologies to assist in the evaluation of some aspect of healthcare data. Some examples include the use of data analytics to assess the level of medication requirements using EHR data (Xu et al, 2019), the use of data analytics to detect anomalies in many areas such as cardiac monitoring (Ukil et al, 2016), and the evaluation and monitoring of data quality in multisite EHR systems (Nobles et al, (2015). Table 2 lists the works in the Information Management theme.

Table 2. Papers focused on the use of big data technologies to promote information management

\begin{tabular}{|c|c|}
\hline Sub-Theme & Author(s) \\
\hline Overview & $\begin{array}{l}\text { Alsinglawi \& Mubin (2019); Chauhan et al (2019); Ghosh \& Scott (2011); } \\
\text { Halder \& Pan (2018); Liu \& Park (2014); Mathew \& Pillai (2015); Menasalvas, } \\
\text { Rodriguez-González \& Gonzalo (2018); Mohamed et al (2020); Nithya \& Ilango } \\
\text { (2017); Patel \& Gandhi (2018); Robinson, Presskila \& Lawrence (2020);Thangaraj, } \\
\text { Ponmalar \& Anuradha (2015); Woodside (2014); Zhu \& Hou (2018) }\end{array}$ \\
\hline Data Management & $\begin{array}{l}\text { Azaria et al (2016); Celesti et al (2016); Chennamsetty, Chalasani \& Riley (2015); } \\
\text { Cronin et al (2017); Hong, Morris \& Seo (2017); Ivan et al (2016); Khazaei et al } \\
\text { (2014); Khennou, Khamlichi \& Chaoui (2016); Lauría \& March (2011); Liu et al } \\
\text { (2019); Liu, Zhang \& Xing (2017); Lu \& Feng (2018); Ma et al (2018); Mamoon } \\
\text { et al (2018); Maria, Sever \& Carlos (2018); Mehmood, Mehmood \& Song (2019); } \\
\text { Mian et al (2014); Nammour, Danas \& Mansour (2016); Nicolau, Alexandru \& } \\
\text { Ianculescu (2019); Nouraei et al (2015a,b); Noussa-Yao, Heudes \& Degoulet } \\
\text { (2018); Perdana et al (2019); Pir, Akram \& Khan (2015a,b); Rathee et al (2019); } \\
\text { Redfield et al (2020); Silvestri et al (2019); Stadler et al (2016); Sudarto et al } \\
\text { (2018); Wilder et al (2020); Weng et al (2017); Ye et al (2018); Zhang et al (2018); } \\
\text { Zhang et al (2017) }\end{array}$ \\
\hline Privacy/Security & $\begin{array}{l}\text { He \& Zeadally (2015); Elhoseny et al (2018); Maheswari \& Vasanthanayaki } \\
\text { (2020); Martinez (2018); Mavroeidakos, Tsolis \& Vergados (2016); Nortey et } \\
\text { al (2019); Patil \& Seshadri (2014); Shi et al (2019); Tang et al (2019); Xu et al } \\
\text { (2019); Yoon-Su \& Seung-Soo (2019) }\end{array}$ \\
\hline Data Evaluation & $\begin{array}{l}\text { Carvalho et al (2019); Nobles et al (2015); Solangi, Aziz \& Asadullah (2015); Ukil } \\
\text { et al (2016); Woodbridge et al (2015); Xu et al (2019) }\end{array}$ \\
\hline
\end{tabular}

The second, and equally large, theme has to do with the use of Big Data technologies to manage hospital resources. The literature reviewed uncovered four classes of asset management tasks addressed by these researchers and they form the four sub-themes. Two of these deal with the utilization of general resources in terms of admisssions and, in the converse, no-shows. More specific asset management activities center on the operating room and the medical equipment used throughout the organization, which will be grouped under the sub-theme of asset management. A good overview of the science of medical asset management can be found in Cui et al (2018) and Pollom, Balvach \& Jones (2007).

The ability to understand and predict the rate of admissions to a specific practice, department, or the hospital in general is the key to being able to predict and control asset allocation, and thus costs. The largest sub-theme in this grouping (45 papers) centers on the use of Big Data technologies to enable healthcare organizations to regulate and predict the flow of patients into the various areas of treatment within the healthcare system. Some examples of these efforts include the use of semisupervised machine learning models to predict the length of stay of hospitalized patients (Livieris et al, (2018), the readmission of diabetic patients using neural networks (Chopra et al, 2017), and the use of machine learning models for the prediction of peak emergency department visit times (Peng et al, 2020). The literature suggests that machine learning has applicability in many areas of patient activity prediction such as predicting the admission of patients with Chronic Obstructive Pulmonary Disease (Orchard et al, 2018), asthma (Luo et al, 2020), and elective spine surgery (Stopa et al, 2019). 
This is but a sample of how machine learning tools (and others) can be used to help level the demand profile and reduce the level of uncertainty for hospital planners.

The management of medical assets such as IV machines and ventilators has long been an area of concern due to the high cost of these items and their importance in the healing of patients. The eleven articles in this sub-theme look specifically at the use of Big Data technologies to improve the availablility and utilization of these important assets. Some studies provide approaches to IoTbased systems that help to locate and manage the usage of wheelchairs (Kurita, Matsuo \& Barolli, 2019), incubators (Kovačević et al, 2019), and rehabilitation equipment (Meng, Zhang \& Yu, 2018). Others apply these tools to the need for predicting maintenance (Shamayleh, Awad \& Farhat, 2020) or monitoring performance (Gurbeta, Badnjević \& Kurta, 2020) of medical equipment.

Certain areas of the hospital have much more specific needs in terms of asset management, such as operating rooms (OR). These are often in short supply and therefore highly sought after, so their proper management is literally a life or death challenge. Three papers examine this problem specifically. Bellini et al (2020) review the use of artificial intelligence and machine learning in OR organization including the prediction of care of perioperative patients with impacts on OR scheduling. Schneider \& Brandeau (2017) use machine learning to improve surgical case length estimation and Fairley, Scheinker \& Brandeau (2019) use machine learning tools to estimate post-anesthesia care of surgical patients to remove patient-flow bottlenecks.

Last, the bane of effective hospital administration is patients that do not show up for scheduled meetings or procedures. This phenomenon is studied by five research teams. Luo et al (2018) use machine learning to identify surgeries with a high risk of cancellation, while no-shows at a community health center are modeled by Mohammadi et al (2018). Levy (2013) uses a predictive tool to understand nonattendance at a specialty clinic. Table 3 displays the papers in this study that focus on resource management.

Table 3. Papers focused on the use of big data technologies to promote resource management

\begin{tabular}{|l|l|}
\hline \multicolumn{1}{|c|}{ Sub-Theme } & \multicolumn{1}{c|}{ Author(s) } \\
\hline Overview & Cui et al (2018); Pollom, Balbach \& Jones (2007) \\
\hline \multirow{5}{*}{ Admissions } & $\begin{array}{l}\text { Allam et al (2019); Alloghani et al (2019); Artetxe et al (2017); Baechle et al } \\
\text { (2020); Barnes et al (2016); Belderrar \& Hazzab (2017); Benbelkacem et al }\end{array}$ \\
& $\begin{array}{l}\text { (2019); Berger et al (2020); Cho et al (2019); Chopra et al (2017); Daghistani } \\
\text { et al (2019); Grana et al (2019);Golas et al (2018); Gowsalya, Krushitha \& } \\
\text { Valliyammai (2014); Helm et al (2016); Hendri \& Sulaiman (2018); Inibhunu } \\
\text { et al (2017); Jeong, Kim \& Shin (2019); Kadri, Baraoui \& Nouaouri (2019); } \\
\text { Karhade et al (2018); Kong et al (2020); Li et al (2014); Lin et al (2019); Livieris } \\
\text { et al (2018a,b); Luo et al (2020); McCoy \& Das (2017); Moyo et al (2018); } \\
\text { Mtonga et al (2019); Nas \& Koyuncu (2019); Nelson et al (2019); Orchard et al } \\
\text { (2018); Peng et al (2020); Roy \& Chin (2014); Shams, Ajorlou \& Yang (2015); } \\
\text { Silva et al (2018); Tesfaye et al (2019); Tideman et al (2019); Turgeman, May } \\
\text { \& Aciulli (2017); Raluy-Callado et al (2018); Stopa et al (2019); Vargheese \& } \\
\text { Viniotis (2014); Wojtusiak, Elashkar \& Nia (2018); Zhang (2019); Zhu, Akkati \& } \\
\text { Hongwattanakul (2016) }\end{array}$ \\
\hline \multirow{5}{*}{ Asset Management } & $\begin{array}{l}\text { Çoban et al (2018); Chai et al (2018); Gurbeta, Badnjeić \& Kurta (2020); } \\
\text { Karthikeyan, Devi \& Valarmathi (2015); Kovačević et al (2019); Kurita, Matsuo } \\
\text { \& Barolli (2019); Meng, Zhang \& Yu (2018); Nutdanai, Pornthip \& Sanpanich } \\
\text { (2016); Patil et al (2016); Ranjbar et al (2019); Shamayleh, Awad \& Farhat (2020) }\end{array}$ \\
\hline \multirow{2}{*}{ Operating Room Mgmt. } & $\begin{array}{l}\text { Bellini et al (2020); Fairley, Scheinker \& Brandeau (2019); Scheinker \& Brandeau } \\
\text { (2017) }\end{array}$ \\
\hline & $\begin{array}{l}\text { Harris, May \& Vargas (2016); Levy (2013); Luo et al (2018); Mohammadi et al } \\
\text { (2018); Simsek, Tiahrt \& Dag (2020) }\end{array}$ \\
\hline & \\
\hline
\end{tabular}


The third theme is only slightly smaller (63 papers) and consists of those papers highlighting Big Data technologies in the management of the hospital or healthcare facility. Once the healing processes are stripped away, the hospital is much like any other business and the same opportunities for improvements in the organizational processes exist. A number of authors have provided useful overviews of the application of Big Data technologies in this realm, including Juswishin (2019), Kane et al (2019), and Kumar \& Suresh (2019). The sub-themes that support a more specific application of these technologies are detailed in the following paragraphs.

As with any other organization, productivity and efficiency are of vital importance. The papers in the largest sub-theme are all related in that they discuss some way in which these technologies might either improve or analyze a hospital's productivity. Fizgerald \& Dadich (2009) use visual analytics to improve hospital scheduling. Xu et al (2017) use machine learning to predict the length of patient stay and time to transition for a specific care unit in a hospital. Gattner, Ekinci \& Schneider (2016) point out the clinical, operational, and financial improvements brought about by the implementation of workflow analytics in healthcare.

Human resources are a critical component of any knowledge-based operation and healthcare is at the top of any list of knowledge-intensive industries. Ouyang, Shan \& Bui (2016) design a RF-based sensor network that provides for the tracking of essential personnel within the hospital for ease of contact. Mesabbah, Abo-Hamad \& McKeever (2019) discuss a hybrid process mining framework that will support complex decision-making during hospital staff planning, and Fischer et al (2020) use IoT and data analytics to support the flexible management of human resources in a smart hospital.

Facilities management processes are often overlooked and more complex than first understood, and they represent a fertile opportunity for these technologies to improve. Ramanathan et al (2020) use IoT to control access to the hospital through its various apertures. Facility layout planning is improved through the use of clinical pathway mining by Arnolds \& Gartner (2018), and Guo et al (2016) use IoT technologies to monitor temperature and humidity in the key areas of a hospital.

When discussing hospital facilities, the conversation often turns to sustainability. This turns out to be another sub-theme of hospital management addressed by researchers. For example, Sahni, Arora \& Dubey (2017) and Golbaz, Nabizadeh \& Sajadi (2019) both take on the management of medical waste, Bacon (2014) addresses the low-carbon hospital design problem using what he calls "occupancy analytics," and Ruiz, Pacheco-Torres \& Casillas (2017) use machine learning to model energy consumption by a hospital.

A few very small sub-themes emerged, as well. Supply chain management using datamining (Hussein et al, 2018) and IoT (Kakkar \& Farshori, 2019) are two examples. A data-driven marketing analysis tool is proposed by Lee et al (2019) to improve pricing and resource allocation. Lastly, two single paper sub-themes on vitally important topics are Mittlestadt's (2017) review of the ethical dimensions of IoT devices and Peng et al's (2017) discussion of an IoT-based risk management system. Table 4 displays the papers that address various hospital management issues using Big Data technologies.

The last theme (32 papers) evident in the literature centers on the impact that Big Data technologies have on patient outcomes. This encompasses the disposition of a patient's medical problem but also the factors that affect these outcomes. There are a number of papers that provide a comprehensive discussion of how Big Data and patient outcomes are related such as Tan et al (2016), Lee et al (2011), and Kachroo, Melek \& Kurian (2013). However, the improvement of patient outcomes has been applied to more specific medical conditions as well as specific areas within the hospital. These applications form the basis of the following sub-themes.

The largest of the sub-themes in this category focuses on patient delay. In this paper, the term patient delay is taken in its broadest sense, encompassing any delay in the movement, treatment, or discharge of a patient from a medical department or facility. It is a clear case of research topics taking root in multiple themes, since this could also be examined through an organizational process lens. In these papers, the thrust was more technical, rather than organizational, hence a different theme. While 
Table 4. Papers focused on the use of big data technologies to improve hospital management

\begin{tabular}{|c|c|}
\hline Sub-Theme & Author(s) \\
\hline Overview & $\begin{array}{l}\text { Couturier et al (2012); Dhanvijay \& Patil (2019); Erickson \& Rothberg (2017); } \\
\text { Guha \& Kumar (2017); Habibzadeh et al (2020); Juswishin (2019); Kane et } \\
\text { al (2019); Kumar \& Suresh (2019); Rathore, Panwar \& Soral (2014); Ratia, } \\
\text { Myllärniemi \& Helander (2019); Stephens (2018); Wills (2014) }\end{array}$ \\
\hline Productivity/Workflow & $\begin{array}{l}\text { Agnihothri, Banderjee \& Thalacker (2015); Ali, Salehnejad \& Mansur (2018); } \\
\text { Almeida (2016); Biehl, Girgensohn \& Patel (2019); Gattner, Ekinci \& Schneider } \\
\text { (2016); Hall \& Partyka (2012); Firzgerald \& Dadich (2009); Katrakazas et al } \\
\text { (2018); Koufi et al (2017); Lee \& Lee (2020); Nukavarapu \& Durbha (2017); } \\
\text { Safdar, Khan \& Shaukat (2019); Sousa et al (2019); Xu et al (2017); Yip et al } \\
\text { (2016) }\end{array}$ \\
\hline Human Resources & $\begin{array}{l}\text { Bala \& Venkatesh (2017); Berkowitz (2017); Cheng \& Kuo (2016); Fischer et al } \\
\text { (2020); Foster et al (2017); Kushniruk \& Borycki (2019); Mesabbah, Abo-Hamad } \\
\text { \& McKeever (2019); Meskó, Hetényi \& Győrffy (2018); Ouyang, Shan \& Bui } \\
\text { (2016); Packianather et al (2019); Rashwan, Fowler \& Arisha (2018); Verma, } \\
\text { Xavier \& Agrawal (2016); Ye et al (2019) }\end{array}$ \\
\hline Facilities Management & $\begin{array}{l}\text { Arnolds \& Gartner (2018); Fatema, Malik \& Iqbal (2020); Gartner \& Padman } \\
\text { (2017); Guo et al (2016); Iqbal, Dar \& Bukhari (2018); Marques, Ferreira \& } \\
\text { Pitarma (2019); Ramanathan et al (2020); Yang et al (2019) }\end{array}$ \\
\hline Sustainability & $\begin{array}{l}\text { Bacon (2014); Baghapour et al (2018); Godpole \& Lamb (2015); Golbaz, } \\
\text { Nabizadeh \& Sajadi (2019); uiz, Pacheco-Torres \& Casillas (2017); Sahni, Arora } \\
\text { \& Dubey (2018) }\end{array}$ \\
\hline Supply Chain Management & $\begin{array}{l}\text { Alotaibi, Mehmood \& Katib (2020); Feng et al (2018); Hussein et al (2019); } \\
\text { Jordan, Dossou \& Chang Jr. (2019); Kakkar \& Farshori (2019) }\end{array}$ \\
\hline Financial Management & Lee et al (2019); Rivera \& DeLaney (2015) \\
\hline Ethics \& Risk Mgmt & Mittelstadt (2017); Peng et al (2017) \\
\hline
\end{tabular}

not a patient outcome per se, it does impact the swiftness of the application of medical activities to the patient and is a strong influencer of patient satisfaction (Price \& Lauffer, 2014). A study using datamining methods to create simulations of coronary patient flows provides a framework within which to improve decision making and training methods (Kovalchuk et al, 2018). Perimal-Lewis and King (2018) describe the process of making data ready for a simulation study of the movement of patients from the ED to the various wards in the hospital. Jiang, Abouee-Mehrizi \& Diao (2020) explore the use of data analytics to support scheduling of patients with complicated conditions based on their clinical priorities.

Because coronary disease is such a large contributor to the total patient load, there have been a number of studies directed at the management of these patients and because it appears as more of a focus than other maladies, it is provided its own sub-theme. For example, Delen, Oztekin, and Tomak (2012) use a data analytic approach to study and predict the complex medical interventions necessary for a successful outcome. A number of supervised machine learning models that help predict the risk of heart disease are compared and verified by Krishnani et al (2019) and Jain and Kaur (2018).

A few minor sub-themes also emerged from the overall category of patient outcomes. The emergency department is the focus of one of them. Raita et al (2019) uses machine learning to predict clinical outcomes and $\mathrm{Hu}$ et al (2017) use it to select patients for more intense case management. Another sub-theme centers on the relationship between staffing and patient outcomes. Leary et al (2016) use datamining to unearth the nonlinear relationship between nurse staffing levels and outcomes while Intensive Care Unit (ICU) staffing is examined to understand how specific staffing characteristics help predict certain patient results. 
A significant number of papers addressed very compelling issues having to do with patient outcomes, but there were not enough of them on any particular topic to create even a very small subtheme. Hopefully, these topics will be expanded upon. Some examples of the "miscellaneous" papers in this theme include the use of machine learning to reduce the number of false alarms in the ICU (Hever et al, 2020), the creation of an in-hospital IoT-based infection management system (Yamashita et al, 2019), and the prediction of hospital-acquired pneumonia (Kuo et al, 2019). Table 5 displays the papers that center on the relationship between Big Data technologies and patient outcomes.

Table 5. Papers focused on the use of big data technologies to promote patient outcomes

\begin{tabular}{|l|l|}
\hline \multicolumn{1}{|c|}{ Sub-Theme } & \multicolumn{1}{c|}{ Author(s) } \\
\hline \multirow{3}{*}{ Overview } & $\begin{array}{l}\text { AbdulGhaffer et al (2020), Atoum \& Al-Jarallah (2019); Krishnan \& Kamath } \\
\text { (2019); Kachroo, Melek \& Kurian (2013); Lee et al (2011); Phillips-Wren \& } \\
\text { McKniff (2019); Sahoo, Mohapatra \& Wu (2017); Seng et al (2016) }\end{array}$ \\
\hline \multirow{3}{*}{ General Patient Delays } & $\begin{array}{l}\text { Cáceres, Rosário \& Amaya (2019); Jiang, Abouee-Mehrizi \& Diao (2020); } \\
\text { Kolesnichenko et al (2017); Kovalchuk et al (2018); Niu et al (2019); primal- } \\
\text { Lewis \& King (2018); Sumarsono, Anshari \& Almunawar (2019) }\end{array}$ \\
\hline Coronary Patient Outcomes & $\begin{array}{l}\text { Delen, Oztekin \& Tomak (2012); Jain \& Kaur (2018); Krishnani et al (2019); } \\
\text { Rajiwall, Chetty \& Davey (2017) }\end{array}$ \\
\hline Emergency Department & Hu et al (2017); Raito et al (2019) \\
\hline Staffing Levels/Patient Outcomes & Leary et al (2016); Zampieri et al (2019) \\
\hline \multirow{2}{*}{ Miscellaneous } & $\begin{array}{l}\text { Chu et al (2018); Chung \& Jung (2019); Hever et al (2020); Kuo et al (2019); } \\
\text { Khaldi et al (2017); Martinez-Millana et al (2019); Parisi, RaviChandran \& } \\
\text { Manaog (2018); Yamashita et al (2019); Zachariadis et al (2018) }\end{array}$ \\
\hline
\end{tabular}

\section{DISCUSSION}

A number of interesting insights can be drawn from the documents analyzed for this project. The first is driven by the types of studies published. Overall, 77 papers in the sample were strickly theoretical or prescriptive in nature, in that the purpose of the study is to either describe an opportunity, describe a need, or to provide an overall description of some aspect of the topic at hand. This means that the remaining papers fell into one of three categories (again, with some overlap):

- Papers that provide a design, framework, or model for a proposed system or tool (62 papers);

- Papers that describe the implementation of a system or tool, either at a prototype or production level of development (27 papers);

- $\quad$ Papers that perform some form of empirical analysis (61 papers).

The high number of design-based papers displays the level of energy being applied to creating systems and tools to improve the administration of healthcare organizations. More importantly, 27 papers discuss the actual implementation of some of these designs so that they can be evaluated for effectivenenss and demonstrated to the key stakeholders in the medical fields. There are a number of implemented systems that provide key capabilities. These include a tool to increase accuracy and efficiency of medical coding using MongoDB (Noussa-Yao et al, 2018), a cloud-based medical equipment management tool that has been implemented in a number of Greek hospitals (Katrakazas et al, 2018), and Rivera and Delaney's (2015) description of a performance management tool at an Orlando hospital. Each of these implementation descriptions provide valuable insight into what has already been done in this field and provide a guide as to what can be done with future research. 
The amount of empirical papers included in the study largely consists of analyses of various aspects of healthcare management (e.g. patient stay prediction) that have been completed using some form of machine learning. In many cases, these studies center on the comparison of multiple machine learning models to see which one created a more accurate prediction. In very view of these papers do the authors apply empirical methods to study the actual usage of Big Data tools in the healthcare administration.

There was an almost even split between papers that centered on technology solutions, resource management, and hospital management. Those efforts regarding patient outcomes showed a relatively distant fourth. This might be due to a lack of interest in the topic, but more likely it has other roots. First, many systems that seek to improve patient outcomes would have been excluded from the study because they would have been primarily clinical in nature, which was one of the gates used to define this particular study. The papers included in the study were focused on management processes that influence patient outcomes, but it is possible that the clinically-focused papers would also have some management themes within them. Also, since the overall reason for the application of Big Data technologies is to improve the services provided to patients, it is entirely reasonable that the papers ending up in the other three categories could also be considered to be "patient outcomes" papers, as well.

The last point to be considered in this body of literature is that while the technological and analytical aspects of healthcare administration have been well covered, there has been relatively little discussion of any changes in organizational processes to adapt to these new tools or to take advantage of them. Many authors discussed the organizational issues at hand when providing justification of their new systems or analyses, but the repercussions for the organization were seldom fully considered. Thus, there appears to be much opportunity for fruitful research to consider how these, and other, data-centric tools might be reflected in the personnel and procedures in the organization.

\section{CONCLUSION}

This analysis provides a detailed overview of the literature surrounding the application of Big Data Technologies, as defined in the beginning of the paper, to the administrative functions of the healthcare industry. By completing this review, the paper makes two contributions to the literature. First, it should serve as a starting point for future researchers to select the organizational area to address as well as lending assistance in the selection of methodology and approach. As noted above, there is a need for a deeper look into the inner workings of the organization as these tools are implemented, including an analysis of implementation techniques to understand the level of involvement of the clinical and administration staff, as well as developing a deeper understanding of the changes in information flow, usage, and control as this new paradigm continues to mature. Moreover, because of the scale of the present study, there was not sufficient space to provide any significant level of detail regarding the strengths and contributions of each paper or a more indepth analysis of those papers that could have been categorized into multiple themes. These, and other research questions such as the contributions of Big Data technologies to the improvement of healthcare performance or the reduction of healthcare costs are fruitful areas for future research that the present paper forms a foundation for.

The second contribution of this study is to inform practitioners and administrators in the healthcare industry of the areas of emphasis that are consuming research resources. In some cases, we see significant involvement by clinical and administrative staff in these papers as coauthors and sources of information, but there is always room for more interdisciplinary research and hopefully studies such as this will provide a strong foundation for those efforts. 


\section{REFERENCES}

AbdulGhaffar, A. A., Mostafa, S. M., Alsaleh, A., Sheltami, T., \& Shakshuki, E. M. (2020). Internet of things based multiple disease monitoring and health improvement system. Journal of Ambient Intelligence and Humanized Computing, 11(3), 1021-1029. doi:10.1007/s12652-019-01204-6

Agnihorthri, S., Banerjee, A., \& Thalacker, G. (2015). Analytics to improve service in a pre-admission testing clinic. Proceedings of the 2015 48th Hawaii International Conference on System Sciences. doi:10.1109/ HICSS.2015.162

Al Mamoon, I., Islam, M. A. K. M., Haque, A. L. M. S., Zeb, A., \& Ahmed, A. (2018). Cognitive radio enabled biomedical and non-medical hospital device communication protocols for cogmed. Proceedings of the 10th International Conference on Electrical and Computer Engineering.

Ali, M., Salehnejad, R., \& Mansur, M. (2018). Hospital productivity: The role of efficiency drivers. The International Journal of Health Planning and Management, 34(2), 806-823. doi:10.1002/hpm.2739 PMID:30729610

Allam, A., Nagy, M., Thoma, G., \& Krauthammer, M. (2018). Neural networks versus logistic regression for 30 days all-cause readmission prediction. Nature, 1-11. doi:10.1038/s41598-019-45685-Z

Alloghani, M., Aljaaf, A., Hussain, A., Baker, T., Mustafina, J., Al-Jumeily, D., \& Khalaf, M. (2019). Implementation of machine learning algorithms to create diabetic patient re-admission profiles. BMC Medical Informatics and Decision Making, 19(253), 1-16. doi:10.1186/s12911-019-0990-x PMID:31830980

Almeida, J. P. (2016). A disruptive big data approach to leverage the efficiency in management and clinical decision support in a hospital. Porto Biomedical Journal, 1(1), 40-42. doi:10.1016/j.pbj.2015.12.001 PMID:32258546

Alotaibi, S., Mehmood, R., \& Katib, I. (2020). The role of big data and twitter data analytics in healthcare supply chain management. In Smart infrastructure and applications (pp. 267-278). Springer Nature Switzerland AG. doi:10.1007/978-3-030-13705-2_11

Alsinglawi, B., \& Mubin, O. (2019). Predictive analytics and deep learning techniques in electronic medical records: recent advancements and future direction. Proceedings of the WAINA 2019. doi:10.1007/978-3-03015035-8_89

Arnolds, I. V., \& Gartner, D. (2018). Improving hospital layout planning through clinical pathway mining. Annals of Operations Research, 263(1-2), 453-477. doi:10.1007/s10479-017-2485-4

Artetxe, A., Grana, M., Beristain, A., \& Rios, S. (2017). Emergency department readmission risk prediction: a case study in Chile. Proceedings of the IWINAC 2017. doi:10.1007/978-3-319-59773-7_2

Atoum, I., \& Al-Jarallah, N. A. (2019). Big data analytics for value-based care: challenges and opportunities. International Journal of Advanced Trends in Computer Science and Engineering, 8(6), 3012-3016. doi:10.30534ijatcse/2019/558622019

Azaria, A., Ekblaw, A., Thiago, V., \& Lippman, A. (2016). Medrec: using blockchain for medical data access and permission management. Proceedings of the 2016 2nd International Conference on Open and Big Data. doi:10.1109/OBD.2016.11

Bacon, M. (2014). Occupancy analytics: a new basis for low-energy-low-carbon hospital design and operation in the UK. Architectural Engineering and Design Management, 10(1-2), 146-163. doi:10.1080-17452007.2013.837254

Baechle, C., Huang, C. D., Agarwal, A., Behara, R. S., \& Goo, J. (2020). Latent topic ensemble learning for hospital readmission cost optimization. European Journal of Operational Research, 281(3), 517-531. doi:10.1016/j.ejor.2019.05.008

Baghapour, M. A., Shooshtarian, M. R., Javaheri, M. R., Dehghanifard, S., Sefidkar, R., \& Nobandegani, A. F. (2018). A computer-based approach for data analyzing in hospital's health- care waste management sector by developing an index using consensus-based fuzzy multi- criteria group decision-making models. International Journal of Medical Informatics, 118, 5-15. doi:10.1016/j.ijmedinf.2018.07.001 PMID:30153921

Bala, H., \& Venkatesh, V. (2017). Employees' reactions to it-enabled process innovations in the age of data analytics in healthcare. Business Process Management Journal, 23(3), 671-702. doi:10.1108/BPMJ-11-2015-0166 
Barnes, S., Hamrock, E., Toerper, M., Siddiqui, S., \& Levin, S. (2015). Real-time prediction of inpatient length of stay for discharge prioritization. Journal of Medical Informatics Association, 23(e1), e2-e10. doi:10.1093/ jamia/ocv106 PMID:26253131

Belderrar, A., \& Hazzab, A. (2017). Hierarchical genetic algorithm and fuzzy radial basis function networks for factors influencing hospital length of stay outliers. Healthcare Informatics Research, 23(3), 226-232. doi:10.4258/ hir.2017.23.3.226 PMID:28875058

Bellini, V., \& Guzzon, M., Bigliardi, B., Mordonini, M., Filippelli, S., \& Bignami, E. (2020). Artificial intelligence: A new tool in operating room management. Role of machine learning models in operating room optimization. Journal of Medical Systems, 44(20), 1-10. doi:10.1007/s10916-019-1512-1 PMID:31823034

Benbelkacem, S., Kadri, F., Atmani, B., \& Chaabane, S. (2019). Machine learning for emergency department management. International Journal of Information Systems in the Service Sector, 11(3), 19-36. doi:10.4018/ IJISSS.2019070102

Berger, J. S., Haskell, L., Ting, W., Lurie, F., Chang, S.-C., Mueller, L. A., Elder, K., Rich, K., Crivera, C., Schein, J. R., \& Alas, V. (2020). Evaluation of machine learning methodology for the prediction of healthcare resource utilization and healthcare costs in patients with critical limb ischemia-Is preventive and personalized approach on the horizon. The EPMA Journal, 11(1), 53-64. doi:10.1007/s13167-019-00196-9 PMID:32140185

Berkowitz, B. (2017). Quality outcomes and credentialing: implication for informatics and big data science. In Big data-enabled nursing (pp. 399-406). Springer International Publishing AG. doi:10.1007/978-3-319-53300-1_20

Biehl, J. T., Girgensohn, A., \& Patel, M. (2019). Achieving accurate room-level indoor location estimation with emerging iot networks. Proceedings of the IoT 2019. doi:10.1145/3365871.3365875

Briner, R. B., \& Denyer, D. (2012). Systematic review and evidence synthesis as a practice and scholarship tool. In D. M. Rousseau (Ed.), The Oxford Handbook of Evidence-Based Management. Oxford University Press.

Caceres, C., Rosario, J. M., \& Amaya, D. (2018). Proposal of a smart hospital based on internet of things (iot) concept. Proceedings of the SaMBa 2018.

Carvalho, J. V., Rocha, A., Vasconcelos, J., \& Abreu, A. (2019). A health data analytics maturity model for hospitals information systems. International Journal of Information Management, 46, 278-235. doi:10.1016/j. ijinfomgt.2018.07.001

Celesti, A., Fazio, M., Romano, A., \& Villari, M. (2016). A hospital cloud-based archival information system for the efficient management of hl7 big data. Proceedings of the MIPRO. doi:10.1109/MIPRO.2016.7522177

Chai, P. R., Zhang, H., Baugh, C. W., Jambaulikar, G. D., McCabe, J. C., Gorman, J. M., Boyer, E. W., \& Landman, A. (2018). Internet of things buttons for real-time notifications in hospital operations: Proposal for hospital implementation. Journal of Medical Internet Research, 20(8), 1-9. doi:10.2196/jmir.9454 PMID:30097420

Chang, H., \& Choi, M. (2016). Big data and healthcare: Building an augmented world. Healthcare Informatics Research, 22(3), 153-155. doi:10.4258/hir.2016.22.3.153 PMID:27525155

Chauhan, S. S., Sharma, I., Kanungo, I., \& Singh, G. (2019). Healthcare data management and analytics using big data tools. International Journal of Innovative Technology and Exploring Engineering, 8(12), 3725-3728. doi:10.35940/ijitee.L2658.1081219

Cheng, C.-H., \& Kuo, Y.-H. (2016). Rfid analytics for hospital ward management. Flexible Services and Manufacturing Journal, 28(4), 593-616. doi:10.1007/s10696-015-9230-6 PMID:32288935

Chennamsetty, H., Chalasani, S., \& Riley, D. (2015). Predictive analytics on electronic health records (ehrs) using hadoop and hive. Proceedings of the IEEE International Conference on Electronics, Computer, and Communication Technologies. doi:10.1109/ICECCT.2015.7226129

Cho, J., Alharin, A., Hu, Z., Fell, N., \& Sartipi, M. (2019). Predicting post-stroke hospital discharge disposition using interpretable machine learning approaches. Proceedings of the 2019 IEEE International Conference on Big Data. doi:10.1109/BigData47090.2019.9006592

Chopra, C., Sinha, S., Jaroli, S., Shukla, A., \& Maheshwari, S. (2017). Recurrent neural networks with non-sequential data to predict hospital readmission of diabetic patients. Proceedings of the ICCBB 2017. doi:10.1145/3155077.3155081 
Chu, J., Dong, W., He, K., Duan, H., \& Huang, Z. (2018). Using neural attention networks to detect adverse medical events from electronic health records. Journal of Biomedical Informatics, 87, 118-130. doi:10.1016/j. jbi.2018.10.002 PMID:30336262

Chung, K., \& Jung, H. (2019). Knowledge-based dynamic cluster model for healthcare management using a convolutional neural network. Information Technology and Management, 1-10. doi:10.1007/s10799-019-00304-1

Coban, S., Gokalp, M. O., Gokalp, E., Eren, P. E., \& Kocyigit, A. (2018). Predictive maintenance in healthcare services with big data technologies. Proceedings of the 2018 IEEE 11th International Conference on ServiceOriented Computing and Applications. doi:10.1109/SOCA.2018.00021

Couturier, J., Sola, D., Borioli, G. S., \& Raiciu, C. (2012). How can the internet of things help to overcome current healthcare challenges. Digiworld Economic Journal, (87), 67-180.

Cronin, R. M., Fabbri, D., Denny, J. C., Rosenbloom, S. T., \& Jackson, G. P. (2017). A comparison of rulebased and machine learning approaches for classifying patient portal messages. International Journal of Medical Informatics, 105, 110-120. doi:10.1016/j.ijmedinf.2017.06.004 PMID:28750904

Cui, L., Xie, X., Shen, Z., Lu, R., \& Wang, H. (2018). Prediction of the healthcare resource utilization using multi-output regression models. IISE Transactions on Healthcare Systems Engineering, 8(4), 291-302. doi:10 $.1080 / 24725579.2018 .1512537$

Cutler, D., Wikler, E., \& Basch, P. (2012). Reducing administrative costs and improving health care system. The New England Journal of Medicine, 367(20), 1875-1878. doi:10.1056/NEJMp1209711 PMID:23150956

Daghistani, T. A., Elshawi, R., Sakr, S., Ahmed, A. M., Al-Thwayss, A., \& Al-Mallah, M. H. (2019). Predictors of in-hospital length of stay among cardiac patients: A machine learning approach. International Journal of Cardiology, 288, 140-147. doi:10.1016/j.ijcard.2019.01.046 PMID:30685103

Delen, D., Oztekin, A., \& Tomak, L. (2012). An analytic approach to better understanding and management of coronary surgeries. Decision Support Systems, 12(3), 698-705. doi:10.1016/j.dss.2011.11.004

Dhanvijay, M., \& Patil, S. C. (2019). Internet of things: A survey of enabling technologies in healthcare and its applications. Computer Networks, 153, 113-131. doi:10.1016/j.comnet.2019.03.006

Elhoseny, M., Shankar, K., Lakshmanaprabu, S. K., Maseleno, A., \& Arunkumar, N. (2018). Hybrid optimization with cryptography encryption for medical image security in internet of things. doi:10.1007/s00521-018-3801-X

Erickson, G. S., \& Rothberg, H. N. (2017). Healthcare and hospitality: Intangible dynamics for evaluation industry sectors. Service Industries Journal, 37(9-10), 589-606. doi:10.1080/02642069.2017.1346628

Fairley, M., Scheinker, D., \& Brandeau, M. L. (2019). Improving the efficiency of the operating room environment with an optimization and machine learning model. Health Care Management Science, 22(4), $756-767$. doi:10.1007/s10729-018-9457-3 PMID:30387040

Feng, Y., Chai, L., Li, X., Zhang, S., \& Song, B. (2018). A distributed procurement cost control scheme of medical material for regional medical consortiums. Proceedings of the MOBIMEDIA 2018. doi:10.4108/eai.216-2018.2276581

Fischer, G. S., da Rosa Righi, R., de Oliveira Ramos, G., de Costa, C. A., \& Rodrigues, J. J. P. C. (2020). Elhealth: Using internet of things and data prediction for elastic management of human resources in smart hospitals. Engineering Applications of Artificial Intelligence, 87, 1-14. doi:10.1016/j.engappai.2019.103285

Fitzgerald, J. A., \& Dadich, A. (2009). Using visual analytics to improve hospital scheduling and patient flow. Journal of Theoretical and Applied Electronic Commerce Research, 4(2), 20-30.

Foster, K., Penninti, P., Shang, J., Kekre, S., Hegde, G. G., \& Venkat, A. (2018). Leveraging big data to balance new key performance indicators in emergency physician management networks. Production and Operations Management, 27(10), 1795-1815. doi:10.1111-poms.12835

Gartner, D., \& Padman, R. (2017). E-hospital-a digital workbench for hospital operations and services planning using information technology and algebraic languages. Proceedings of the MEDINFO 2017. 
Gattnar, E., Ekinci, O., \& Schneider, J. (2016). Leveraging the value for health care providers using clinical workflow analytics. In Boundaryless hospital (pp. 201-209). Springer-Verlang Berlin Heidelberg. doi:10.1007/9783-662-49012-9_11

Ghosh, B., \& Scott, J. E. (2011). Antecedents and catalysts for developing a healthcare analytic capability. Communications of the Association for Information Systems, 29, 395-410. doi:10.17705/1CAIS.02922

Godbole, N. S., \& Lamb, J. (2015). Using data science \& big data analytics to make healthcare green. Proceedings of the 12th International Conference \& Expo on Emerging Technologies For a Smarter World. doi:10.1109/ CEWIT.2015.7338161

Golas, S. B., Shibahara, T., Agboola, S., Otaki, H., Sato, J., Nakae, T., \& Jethwani, K. et al. (2018). A machine learning model to predict the risk of 30-day readmissions in patients with heart failure: A retrospective analysis of electronic medical records data. BMC Medical Informatics and Decision Making, 18(44), 1-17. doi:10.1186/ s12911-018-0620-z PMID:29929496

Golbaz, S., Nabizadeh, R., \& Sajadi, H. S. (2019). Comparative study of predicting hospital solid waste generation using multiple linear regression and artificial intelligence. Journal of Environmental Health Science \& Engineering, 17(1), 41-51. doi:10.1007/s40201-018-00324-z PMID:31297201

Gowsalya, M., Krushitha, K., \& Valliyammai, C. (2014). Predicting the risk of readmission of diabetic patients using MapReduce. Proceedings of the 2014 Sixth International Conference on Advanced Computing (ICoAC). doi:10.1109/ICoAC.2014.7229729

Grana, M., Lopez-Guede, J. M., Irazusta, J., Labayen, I., \& Besga, A. (2019). Modelling hospital readmissions under frailty conditions for healthy aging. Expert Systems: International Journal of Knowledge Engineering and Neural Networks, 1-10. doi:10.1111/exsy.12437

Guhu, S., \& Kumar, S. (2018). Emergence of big data research in operations management, information systems, and healthcare: Past contributions and future roadmap. Production and Operations Management, 27(9), 1724-1735. doi:10.1111/poms.12833

Guo, B., Wang, X., Zhang, X., Yang, J., \& Wang, Z. (2016). Research on the temperature \& humidity monitoring system in the key areas of the hospital based on the internet of things. International Journal of Smart Home, 10(7), 205-2016. doi:10.14257/ijsh.2016.10.7.21

Gurbeta, L., Badnjevic, A., \& Kurta, E. (2019). Everlab: Software tool for medical device safety and performance inspection management. Proceedings of the CMBEBIH 2019.

Habibzadeh, H., Dinesh, K., Shishvan, O. R., Boggio-Dandry, A., Sharma, G., \& Soyata, T. (2020). A survey of healthcare internet of things (HIoT): A clinical perspective. IEEE Internet of Things Journal, 7(1), 53-71. doi:10.1109/JIOT.2019.2946359

Halder, P., \& Pan, I. (2018). Role of big data analysis in healthcare sector: a survey. Proceedings of the 2018 Fourth International Conference on Research in Computational Intelligence and Communications Networks (ICRCICN). doi:10.1109/ICRCICN.2018.8718684

Hall, R., \& Partyka, J. (2012). How analytics and o.R. Driven tools help healthcare organizations move from "Tracking" Mentality to "Delivery and logistics." Informs, 39(3), 1-8.

Harris, S. L., May, J. H., \& Vargas, L. G. (2016). Predictive analytics model for healthcare planning and scheduling. European Journal of Operational Research, 253(1), 121-131. Advance online publication. doi:10.1016/j. ejor.2016.02.017

He, D., \& Zeadally, S. (2015). An analysis of RFID authentication schemes for internet of things in healthcare environment using elliptic curve cryptography. IEEE Internet of Things Journal, 2(1), 72-83. doi:10.1109/ JIOT.2014.2360121

Helm, J. E., Alaeddini, A., Stauffer, J. M., Bretthauer, K. M., \& Skolarus, T. A. (2016). Reducing hospital readmissions by integrating empirical prediction with resource optimization. Production and Operations Management, 25(2), 233-257. doi:10.1111/poms.12377 
Hendri, H. J. M., \& Sulaiman, H. (2018). Predictive modeling for dengue patient's length of stay (los) using big data analytics (bda). In Recent trends in information and communication technology (pp. 12-19). Springer International Publishing.

Hever, G., Cohen, L., O’Connor, M. F., Matot, I., Lerner, B., \& Bitan, Y. (2020). Machine learning applied to multi-sensor information to reduce false alarm rate in the icu. Journal of Clinical Monitoring and Computing, 34(2), 339-352. doi:10.1007/s10877-019-00307-x PMID:30955160

Hong, J., Morris, P., \& Seo, J. (2017). Interconnected personal health record ecosystem using iot cloud platform and hl7 fhir. Proceedings of the 2017 IEEE International Conference on Healthcare Informatics. doi:10.1109/ ICHI.2017.82

Hu, X., Barnes, S., Bharnadottir, M., \& Golden, B. (2017). Intelligent selection of frequent emergency department patients for case management: A machine learning framework based on claims data. IISE Transactions on Healthcare Systems Engineering, 7(3), 130-143. doi:10.1080/24725579.2017.1351502

Hussein, B. R., Kasem, A., Omar, S., \& Siau, N. Z. (2019). A data mining approach for inventory forecasting: a case study of medical store. Proceedings of the CIIS 2018. doi:10.1007/978-3-030-03302-6_16

Inibhunu, C., Schauer, A., Redwood, O., Clifford, P., \& McGregor, C. (2017). Predicting hospital admissions and emergency room visits using remote home monitoring data. Proceedings of the IEEE Life Sciences Conference. doi:10.1109/LSC.2017.8268198

Iqbal, U., Dar, M. A., \& Bukhari, S. N. (2018). Intelligent hospitals based on iot. Proceedings of the 4th International Conference on Advances in Electrical, Electronics, Information, Communication and BioInformatics (AEEICB-18). doi:10.1109/AEEICB.2018.8480947

Ivan, M.-L., Velicanu, M., Trifu, M. R., \& Ciurea, C. (2016). Using business intelligence tools for predictive analytics in healthcare system. (IJACSA). International Journal of Advanced Computer Science and Applications, 7(5), 178-182. doi:10.14569/IJACSA.2016.070527

Jain, P., \& Kaur, A. (2018). Big data analysis for prediction of coronary artery disease. Proceedings of the 2018 4th International Conference on Computing Sciences. doi:10.1109/ICCS.2018.00038

Jeong, Y.-S., Kim, D.-R., \& Shin, S.-S. (2019). An efficient patient information transmission and receiving scheme using cloud h-IoT system. International Journal of Recent Technology and Engineering, 8(2S6), 180184. doi:10.35940/ijrte.B1034.0782S619

Jiang, Y., Abouee-Mehrizi, H., \& Diao, Y. (2020). Data-driven analytics to support scheduling of multi-priority multi-class patients with wait time targets. European Journal of Operational Research, 281(3), 597-611. doi:10.1016/j.ejor.2018.05.017

Jordan, K., Dossou, P.-E., \& Chang, J. Jr. (2019). Using lean manufacturing and machine learning for improving medicines procurement and dispatching in a hospiital. Procedia Manufacturing, 38, 1034-1041. doi:10.1016/j. promfg.2020.01.189

Juzwishin, D. W. M. (2019). Big data challenges from a healthcare administration perspective. In Big data, big challenges: a healthcare perspective (pp. 55-67). Springer Nature Switzerland. doi:10.1007/978-3-030-06109-8_5

Kachroo, S., Melek, W. W., \& Kurian, C. J. (2013). Evaluation of predictive learners for cancer incidence and mortality. Proceedings of the 4th IEEE International Conference on E-Health and Bioengineering. doi:10.1109/ EHB.2013.6707388

Kadri, F., Baraoui, M., \& Nouaouri, I. (2019). An LSTM-based deep learning approach with application to predicting hospital emergency department admissions. Proceedings of the International Conference on Industrial Engineering and Systems Management. doi:10.1109/IESM45758.2019.8948130

Kakkar, A., \& Farshori, A. (2019). Collaborative medical inventory resources using edge computing-a solution to serve critical healthcare requirements at public hospitals. Proceedings of the Amity International Conference on Artificial Intelligence. doi:10.1109/AICAI.2019.8701242

Kane, E. M., Scheulen, J. J., Puttgen, A., Martinez, D., Levin, S., Bush, B. A., . . Efron, D. T. (2019). Use of systems engineering to design a hospital command center. Joint Commission Journal on Quality and Patient Safety, 45, 370-379. doi:10.1016/j.jcjq.2018.11.006 PMID:30638974 
Karhade, A. V., Ogink, P., Thio, Q., Broekman, M., Cha, T., Gormley, W. B., Hershman, S., Peul, W. C., Bono, C. M., \& Schwab, J. H. (2018). Development of machine learning algorithms for prediction of discharge disposition after elective inpatient surgery for lumbar degenerative disc disorders. Neurosurgical Focus, 45(5), E6. Advance online publication. doi:10.3171/2018.8.FOCUS18340 PMID:30453463

Karthikeyan, S., \& Devi, K. V. (2015). Internet of things: hospice appliances monitoring and control system. Proceedings of the Online International Conference on Green Engineering and Technologies. doi:10.1109/ GET.2015.7453776

Katrakazas, P., Costarides, V., Tarousi, M., Christodoulakis, M., Tournpaniaris, P., Pavlopoulos, S., ... Koutsouris, D. (2018). Business process modeling for a Greek hospitals' medical equipment data center. Proceedings of the 2018 IEEE 31st International Symposium on Computer-Based Medical Systems.

Khaldi, R., El Afia, A., Chiheb, R., \& Ensias, R. F. (2017). Artificial neural network based approach for blood demand forecasting: fez transfusion blood center case study. Proceedings of the BDCA 2017. doi:10.1145/3090354.3090415

Khazaei, H., McGregor, C., Eklund, M., El-Khatib, K., \& Thommandram, A. (2014). Toward a big data healthcare analytics system: a mathematical modeling perspective. Proceedings of the 2014 IEEE 10th World Congress on Services. doi:10.1109/SERVICES.2014.45

Khennou, F., Khamlichi, Y. I., \& Chaoui, N. E. H. (2016). Designing a health data management system based hadoop-agent. Proceedings of the 4th IEEE International Colloquium on Information Science and Technology. doi:10.1109/CIST.2016.7804983

Kolesnichenko, O., Smorodin, G., Mazelis, A., Nikolaev, A., Mazelis, L., Martynov, A., \& Kolesnichenko, Y. et al. (2017). Ipatient in medical informations systems and future of internet of health. Proceedings of the The 20th Conference of FRUCT Association. doi:10.23919/FRUCT.2017.8071308

Kong, G., Xu, D.-L., Yang, J.-B., Wang, T., \& Jiang, B. (2020). Evidential reasoning rule-based decision support system for predicting icu admission and in-hospital death of trauma. IEEE Transactions on Systems, Man, and Cybernetics. Systems, 1-12. doi:10.1109/TSMC.2020.2967885

Kovacevic, Z., Pokvic, L. G., Spahic, L., \& Badnjevic, A. (2019). Prediction of medical device performance using machine learning techniques: Infant incubator case study. Health and Technology, 1-5. Advance online publication. doi:10.1007/s12553-019-00386-5

Kovalchuk, S. V., Funkner, A. A., Metsker, O. G., \& Yakovlev, A. (2018). Simulation of patient flow in multiple healthcare units using process and data mining techniques for model identification. Journal of Biomedical Informatics, 82, 128-142. doi:10.1016/j.jbi.2018.05.004 PMID:29753874

Krishnan, G. S., \& S., S. K. (2019). A novel GA-ELM model for patient-specific mortality prediction over largescale lab event data. Applied Soft Computing, 80, 525-533. doi:10.1016/j.asoc.2019.04.019

Krishnani, D., Kumari, A., Dewangan, A., Singh, A., \& Naik, N. S. (2019). Prediction of coronary heart disease using supervised machine learning algorithms. Proceedings of the IEEE Region 10 Conference. doi:10.1109/ TENCON.2019.8929434

Kumar, N. A. J., \& Suresh, S. (2019). A proposal of smart hospital management using hybrid cloud, IoT, ML, and AI. Proceedings of the Fourth International Conference on Communication and Electronics Systems (ICCES 2019).

Kuo, K. M., Talley, P. C., Huang, C. H., \& Cheng, L. C. (2019). Predicting hospital-acquired pneumonia among schizophrenic patients: A machine learning approach. BMC Medical Informatics and Decision Making, 19(42), 1-8. doi:10.1186/s12911-019-0792-1 PMID:30866913

Kurita, T., Matsuo, K., \& Barolli, L. (2019). A wheelchair management system using iot senors and agile-kanban. Proceedings of the INCoS 2019.

Kushniruk, A. W., \& Borycki, E. M. (2019). Big data challenges from a human factors perspective. In Big data, big challenges: a healthcare perspective (pp. 91-99). Springer Nature Switzerland. doi:10.1007/978-3-030-06109-8_8 
Lauria, E. J. M., \& March, A. D. (2011). Combining bayesian text classification and shrinkage to automate healthcare coding: A data quality analysis. ACM Journal of Data and Information Quality, 2(3), 1-22. doi:10.1145/2063504.2063506

Leary, A., Cook, R., Jones, S., Smith, J., Gough, M., Maxwell, E., Punshon, G., \& Radford, M. (2016). Mining routinely collected acute data to reveal non-linear relationships between nurse staffing levels and outcomes. BMJ Open, 6(12), 1-7. doi:10.1136/bmjopen-2016-011177 PMID:27986733

Lee, C. S., Tiong, A., Tang, W. L., \& Yap, K. H. (2019). Data-driven "Market basket"-pricing and personalized health information services using salesforce's model-driven systems service design. Proceedings of the IEEE International Conference on Industrial Engineering and Engineering Management. doi:10.1109/ IEEM44572.2019.8978835

Lee, N., Laine, A. F., Hu, J., Wang, F., Sun, J., \& Ebadollahi, S. (2011). Mining electronic medical records to explore the linkage between healthcare resource utilization and disease severity in diabetic patients. Proceedings of the 2011 First IEEE International Conference on Healthcare Informatics, Imaging and Systems Biology. doi:10.1109/HISB.2011.34

Lee, S., \& Lee, Y. H. (2020). Improving emergency department efficiency by patient scheduling using deep reinforcement learning. Health Care, 1-17. doi:10.3390/healthcare8020077 PMID:32230962

Levy, V. (2013). A predictive tool for nonattendance at a specialty clinic. Proceedings of the 10th International Conference and Expo on Emerging Technologies for a Smarter World.

Li, Y., Sun, N., Wu, F., Zheng, C., \& Li, Y. (2014). Predictive analysis of outpatient visits to a grade 3, class a hospital using arima model. Proceedings of the 2014 International Symposium on Information Technology (ISIT 2014).

Lin, Y.-W., Zhou, Y., Faghri, F., Shaw, M. J., \& Campbell, R. H. (2019). Analysis and prediction of unplanned intensive care unit readmission using recurrent neural networks with long short-term memory. PLoS One, 14(7), e0218942. Advance online publication. doi:10.1371/journal.pone.0218942 PMID:31283759

Liu, J., Zhang, Y., \& Xing, C. (2017). Medical big data web service management platform. Proceedings of the 2017 IEEE 11th International Conference on Semantic Computing. doi:10.1109/ICSC.2017.69

Liu, W., \& Park, E. K. (2014). Big data as an e-health service. Proceedings of the International Conference on Computing, Networking and Communications.

Liu, Y., Zhang, L., Yang, Y., Zhou, L., Ren, L., Wang, F., Liu, R., Pang, Z., \& Deen, M. J. (2019). A novel cloud-based framework for the elderly healthcare services using digital twin. IEEE Access: Practical Innovations, Open Solutions, 7, 49088-49101. doi:10.1109/ACCESS.2019.2909828

Livieris, I. E., Dimopoulos, I. F., Kotsilieris, T., \& Pintelas, P. (2018). Predicting length of stay in hospitalized patients using ssl algorithms. Proceedings of the DSAI 2018. doi:10.1145/3218585.3218588

Livieris, I. E., Kotsilieris, T., Dimopoulos, I., \& Pintelas, P. (2018). Decision support software for forecasting patient's length of stay. Algorithms, 11(199). Advance online publication. doi:10.3390/a11120199

Lu, C., \& Feng, L. (2018). Design and implementation of resident health record management system based on big data technology. Proceedings of the 2018 11th International Conference on Intelligent Computation Technology and Automation. doi:10.1109/ICICTA.2018.00073

Luo, G., He, S., Stone, B. L., Nkoy, F. L., \& Johnson, M. D. (2020). Developing a model to predict hospital encounters for asthma in asthmatic patients: Secondary analysis. JMIR Medical Informatics, 8(1), 1-16. doi:10.2196/16080 PMID:31961332

Luo, L., Zhang, F., Yao, Y., \& Gong, R. (2018). Machine learning for identification of surgeries with high risks of cancellations. Health Informatics Journal, 1-15. doi:10.1177/1460458218813602 PMID:30518275

Ma, X., Wang, Z., Zhou, S., Wen, H., \& Zhang, Y. (2018). Intelligent healthcare systems assisted by data analytics and mobile computing. Proceedings of the 14th International Wireless Communications and Mobile Computing Conference. doi:10.1109/IWCMC.2018.8450377

Maria, A. R., Sever, P., \& Carlos, V. (2018). Cloud computing for big data from biomedical sensors monitoring, storage and analyze. Proceedings of the Conference on Grid, Cloud, \& High Performance Computing in Science. 
Marques, G., Ferreira, C. R., \& Pitarma, R. (2019). Indoor air quality assessment using a co2 monitoring system based on internet of things. Journal of Medical Systems, 43(67), 1-10. doi:10.1007/s10916-019-1184-x PMID:30729368

Martinez, J. B. Medical device security in the iot age. Proceedings of the 9th IEEE Annual Ubiquitous Computing, Electronics and Mobile Communication Conference. doi:10.1109/UEMCON.2018.8796531

Martinez-Millana, A., Lizondo, A., Gatta, R., Traver, V., \& Fernandez-Llatas, C. (2018). Expectations from a process mining dashboard in operating rooms with analytic hierarchy process. Proceedings of the BPM 2018 Workshops.

Mathew, P. S., \& Pillai, A. S. (2015). Big data solutions in healthcare: problems and perspectives. Proceedings of the IEEE Sponsored 2nd International Conference on Innovations in Information Embedded and Communications Systems. doi:10.1109/ICIIECS.2015.7193211

Mavroeidakos, T., Tsolis, N., \& Vergados, D. D. (2016). Centralized management of medical big data in intensive care unit: a security analysis. Proceedings of the 3rd Smart Cloud Networks \& Systems. doi:10.1109/ SCNS.2016.7870557

McCoy, A., \& Das, R. (2017). Reducing patient mortality, length of stay and readmissions through machine learning-based sepsis prediction in the emergency department, intensive care unit and hospital floor units. $B M J$ Open Quality, 6(2), 1-7. doi:10.1136/bmjoq-2017-000158 PMID:29450295

Mehmood, A., Mehmood, F., \& Song, W.-C. (2019). Cloud based e-prescription management system for healthcare services using IoT devices. Proceedings of the International Conference on Information and Communication Technology Convergence. doi:10.1109/ICTC46691.2019.8939916

Menasalvas, E., Rodriguez-Gonzalez, \& Gonzalo, C. (2018). Mining electronic health records: challenges and impact. Proceedings of the 2018 14th International Conference on Signal-Image Technology \& Internet-Based Systems (SITIS).

Meng, Q., Zhang, H., \& Yu, H. (2018). The internet of things-based rehabilitation equipment monitoring system. Proceedings of the AIAAT 2018. doi:10.1088/1757-899X/435/1/012015

Mesabbah, M., \& Abo-Hamad, w. (2019). A hybrid process mining framework for automated simulation modelling for healthcare. Proceedings of the 2019 Winter Simulation Conference. doi:10.1109/WSC40007.2019.9004800

Mesko, B., Hetenyi, G., \& Gyorffy, Z. (2018). Will artificial intelligence solve the human resource crisis in healthcare? BMC Health Services Research, 18(545), 1-5. doi:10.1186/s12913- 018-3359-4 PMID:30001717

Mian, M., Teredesai, A., Hazel, D., Pokuri, S., \& Uppala, K. (2014). Work in progress-in- memory analysis for healthcare big data. Proceedings of the 2014 IEEE International Congress on Big Data. doi:10.1109/BigData. Congress.2014.119

Mittelstadt, B. (2017). Ethics of the health-related internet of things: A narrative review. Ethics and Information Technology, 19(3), 157-175. doi:10.1007/s10676-017-9426-4

Mohamed, A., Najafabadi, M. K., Wah, Y. B., Zaman, E. A. K., \& Maskat, R. (2020). The state of the art and taxonomy of big data analytics: View from new big data framework. Artificial Intelligence Review, 53(2), 989-1037. doi:10.1007/s10462-019-09685-9

Mohammadi, I., Wu, H., Turkcan, A., Tocos, T., \& Doebbeling, B. N. (2018). Data analytics and modeling for appointment no-show in community health centers. Journal of Primary Care \& Community Health, 9, 111. doi:10.1177/2150132718811692 PMID:30451063

Mtonga, K., Kumaran, S., Mikeka, C., Jayavel, K., \& Nsenga, J. (2019). Machine learning-based patient load prediction and IoT integrated intelligent patient transfer systems. Future Internet, 11(236), 1-24. doi:10.3390/ fi11110236

Nammour, F., Danas, K., \& Mansour, N. (2016). CorporateMeasures: A clinical analytics framework leading to clinical intelligence. Proceedings of the 2016 IEEE 18th international conference on e-health networking, applications and services. doi:10.1109/HealthCom.2016.7749451 
Nas, S., \& Koyuncu, M. (2019). Emergency department capacity planning: A recurrent neural network and simulation approach. Computational and Mathematical Methods in Medicine, 2019, 1-13. doi:10.1155/2019/4359719 PMID:31827585

Nelson, A., Herron, D., Rees, G., \& Nachev, P. (2019). Predicting scheduled hospital attendance with artificial intelligence. Digital Medicine, 1-7. doi:10.1038/s41746-019-0103-3

Nicolau, D. N., Alexandru, A., \& Ianculescu, M. (2019). An iot, virtual machines and cloud computing-based framework for an optimal management of healthcare cata collected from a smart environment. A case study: Ro-smart ageing project. Informações Econômicas, 23(3), 72-83. doi:10.12948/issn14531305/23.3.2019.07

Nithya, B., \& Ilango, V. (2017). Predictive analytics in health care using machine learning tools and techniques. Proceedings of the International Conference on Intelligent Computing and Control Systems ICICCS 2017. doi:10.1109/ICCONS.2017.8250771

Niu, W., Huang, J., Xing, Z., \& Chen, J. (2019). Knowledge spillovers of medical big data under hierarchical medical system and patients' medical treatment decisions. IEEE Access: Practical Innovations, Open Solutions, 7, 55770-55779. doi:10.1109/ACCESS.2019.2908440

Nobles, A. L., Vilankar, K., Wu, H., \& Barnes, L. E. (2015). Evaluation of data quality of multisite electronic health record data for secondary analysis. Proceedings of the 2015 IEEE International Conference on Big Data. doi:10.1109/BigData.2015.7364060

Nortey, R. N., Yue, L., Agdedanu, P. R., \& Adjeisah, M. (2019). Privacy module for distributed electronic health records (EHRS) using the blockchain. Proceedings of the 2019 The 4th IEEE International Conference on Big Data Analytics. doi:10.1109/ICBDA.2019.8713188

Nouraei, S. A. R., Hudovsky, A., Frampton, A. E., Mufti, U., White, N. B., Wathen, C. G., Sandhu, G. S., \& Darzi, A. (2015). A study of clinical coding accuracy in surgery. Annals of Surgery, 261(6), 1096-1107. doi:10.1097/ SLA.0000000000000851 PMID:25470740

Nouraei, S. A. R., Virk, J. S., Hudovsky, A., Wathan, C., Dari, A., \& Parsons, D. (2015). Accuracy of clinicianclinical coder information handover following acute medical admissions: Implication for using administrative datasets in clinical outcomes management. Journal of Public Health, 38(2), 352-362. doi:10.1093/pubmed/ fdv041 PMID:25907271

Nukavarapu, N., \& Durbha, S. (2017). Geo-visual analytics for healthcare critical infrastructure simulation model. Proceedings of the IGARSS 2017. doi:10.1109/IGARSS.2017.8128402

Nutdanai, S., \& Sanpanich, A. (2016). Development of an information system for medical equipment management in hospitals. Proceedings of the 2016 Biomedical Engineering International Conference (BMEiCON-2016). doi:10.1109/BMEiCON.2016.7859583

Nuzhat, F., Hasmat, M., \& Atif, I. (2020). Big-data analytics based energy analysis and monitoring for multistorey hospital buildings: case study. In H. Malik (Ed.), Soft computing in condition monitoring and diagnostics of electrical and mechanical systems, advances in intelligent systems (pp. 325-343). Springer Nature Singapore Pte.

Orchard, P., Agakova, A., Pinnock, H., Burton, C. D., Sarran, C., Agakov, F., \& McKinstry, B. (2018). Improving prediction of risk of hospital admission in chronic obstructive pulmonary disease: Application of machine learning to telemonitoring data. Journal of Medical Internet Research, 20(9), 1-11. doi:10.2196/jmir.9227 PMID:30249589

Otokiti, A. (2019). Using informatics to improve healthcare quality. International Journal of Health Care Quality Assurance, 32(2), 425-430. doi:10.1108/IJHCQA-03-2018-0062 PMID:31017059

Ouyang, Y., Shan, K., \& Bui, F. M. (2016). An rf-based wearable sensor system for indoor tracking to facilitate efficient healthcare management. Proceedings of the 38th Annual International Conference of the IEEE Engineering in Medicine. doi:10.1109/EMBC.2016.7591808

Packianather, M. S., Munizaga, N. L., Zouwail, S., \& Saunders, M. (n.d.). Development of soft computing tools and iot for improving the performance assessment of analysers in a clinical laboratory. Proceedings of the 14 Annual Conference of Systems Engineering.

Parisi, L., RaviChandran, N., \& Manaog, M. L. (2018). Decision support system to improve postoperative discharge: A novel multi- class classification approach. Knowledge-Based Systems, 152, 1-10. doi:10.1016/j. knosys.2018.03.033 
Pashazadeh, A., \& Navimipour, N. J. (2018). Big data handling mechanisms in the healthcare applications: A comprehensive and systematic literature review. Journal of Biomedical Informatics, 82, 47-62. doi:10.1016/j. jbi.2018.03.014 PMID:29655946

Patel, H. B., \& Gandhi, S. (2018). A review on big data analytics in healthcare using machine learning approaches. Proceedings of the 2nd International Conference on Trends in electronics and Informatics (ICOEI 2018). doi:10.1109/ICOEI.2018.8553788

Patil, H. K., \& Seshadri, R. (2014). Big data security and privacy issues in healthcare. Proceedings of the 2014 IEEE International Congress on Big Data. doi:10.1109/BigData.Congress.2014.112

Patil, M. A., Patil, R. B., Krishnamoorthy, P., \& John, J. (2016). A machine learning framework for auto classification of imaging system exams in hospital setting for utilization optimization. Proceedings of the 38th Annual International Conference of the IEEE Engineering in Medicine and Biology Society. doi:10.1109/ EMBC.2016.7591219

Peng, J., Chen, C., Zhou, M., Xie, X., Zhou, Y., \& Luo, C.-H. (2002). Peak outpatient and emergency department visit forecasting for patients with chronic respiratory diseases using machine learning methods: Retrospective cohort study. JMIR Medical Informatics, 8(8), 1-8. doi:10.2196/13075

Peng, S., Su, G., Chen, J., \& Du, P. (2017). Design of an iot-bim-gis based risk management system for hospital basic operation. Proceedings of the 2017 IEEE Symposium on Service-Oriented System Engineering. doi:10.1109/ SOSE.2017.22

Perdana, T. R., Mujiatun, S., Sfenrianto, S., \& Kaburuan, E. R. (2019). Designing knowledge management system with big data for hospital inpatient services (case study at Islamic hospital xyz pekanbaru). Proceedings of the 2019 International Conference on Information and Communications Technology (ICOIACT). doi:10.1109/ ICOIACT46704.2019.8938469

Perimal-Lewis, L., \& King, B. (2018). Patient journey modelling: is a single continuous clinical care venue essential to good patient outcomes? A retrospective analysis of administrative data enhanced with detailed clinical care review. Proceedings of the ACSW. doi:10.1145/3167918.3167957

Phillips-Wren, G., \& McKniff, S. (2019). Aligning operational benefits of big data analytics and organizational culture at Wellspan health. In T. D. M. Anandarajan (Ed.), Aligning business strategies and analytics (pp. 115-131). Springer International Publishing. doi:10.1007/978-3-319-93299-6_8

Pir, A., Akram, M. U., \& Khan, M. A. (2015a). Internet of things based context awareness architectural framework for HMIS. Proceedings of at the 2015 IEEE 17th International Conference on e-Health Networking, Applications and Services. doi:10.1109/HealthCom.2015.7454473

Pir, A., Akram, M. U., \& Khan, M. A. (2015b). Survey based analysis of internet of things based architectural framework for hospital management system. Proceedings of the 2015 13th International Conference on Frontiers of Information Technology.

Pollom, R. K., Balbach, J., \& Jones, K. A. (2007). Clinical analytics equal better systemwide outcomes. Nursing Management, 44-48. PMID:18188008

Price, S., \& Lauffer, V. (2014). Increasing patient satisfaction by empowering staff to manage delays. Journal of Perianesthesia Nursing, 29(5), e25. doi:10.1016/j.jopan.2014.08.085

Raita, Y., Goto, T., Faridi, M. K., Brown, D. F. M., Camargo, C. A. Jr, \& Hasegawa, K. (2019). Emergency department triage prediction of clinical outcomes using machine learning models. Critical Care (London, England), 23(64), 1-13. doi:10.1186/s13054-019-2351-7 PMID:30795786

Rajliwall, N. S., Girija, C., \& Davey, R. (2017). Chronic disease risk monitoring based on an innovative predictive modelling framework. Proceedings of the IEEE Symposium Series on Computational Intelligence. doi:10.1109/ SSCI.2017.8285257

Raluy-Callado, M., Cox, A., MacLachlan, S., Bakheit, A. M., Moore, A. P., Dinet, J., \& Gabriel, S. (2018). A retrospective study to assess resource utilization and costs in patients with post- stroke spasticity in the united kingdom. Current Medical Research and Opinion, 34(7), 1317-1324. doi:10.1080/03007995.2018.1447449 PMID:29490512 
Ramanathan, L., Swarnalatha, P., Ramani, S., Prabakaran, N., Phogat, P. S., \& Rajkumar, S. (2020). Secured smart hospital cabin door knocker using internet of things (iot). In Smart healthcare analytics in IoT enabled environment (pp. 77-89). Springer Nature Switzerland.

Ranjbar, E., Sedehi, G., Rashidi, M., \& Suratgar, A. A. (2019). Design of an iot-based system for smart maintenance of medical equipment. Proceedings of the Third International Conference on Internet of Things and Applications. doi:10.1109/IICITA.2019.8808841

Rashwan, W., Fowler, J., \& Arisha, A. (2018). A multi-method scheduling framework for medical staff. Proceedings of the 2018 Winter Simulation Conference. doi:10.1109/WSC.2018.8632247

Rathee, G., Sharma, A., Saini, H., Kumar, R., \& Iqbal, R. (2019). A hybrid framework for multimedia data processing in IoT-healthcare using blockchain technology. Multimedia Tools and Applications, 1-23. doi:10.1007/ s11042-019-07835-3

Rathore, S., Panwar, A., \& Soral, P. (2014). Critical factors for successful implementation of business analytics: Exploratory findings from select cases. International Journal of Business Analytics and Intelligence, 2(2), 11-23.

Ratia, M., Myllarniemi, J., \& Helander, N. (2019). The potential beyond IC 4.0: The evolution of business intelligence towards advanced business analytics. Measuring Business Excellence, 23(4), 396-410. doi:10.1108/ MBE-12-2018-0103

Redfield, C., Tlimat, A., Haplern, Y., Schoenfeld, D. W., Ullman, E., Sontag, D. A., \& Horng, S. et al. (2020). Deriviation and validation of a machine learning record linkage algorithm between emergency medical services and the emergency department. Journal of the American Medical Informatics Association, 27(1), $147-153$. doi:10.1093/jamia/ocz176 PMID:31605488

Rivera, J., \& Delaney, S. (2015). Using business analytics to improve outcomes. Healthcare Financial Management, 69(2), 64-67. PMID:26665541

Robinson, Y. H., Presskila, A., \& Samraj, L. T. (2020). Utilization of internet of things in health care information system. In Internet of things and big data applications (pp. 35-46). Springer Nature Switzerland.

Roy, S. B., \& Chin, S.-C. (2014). Prediction and management of readmission risk for congestive heart failure. Proceedings of the Health Informatics (HEALTHINF-2014).

Ruiz, E., Pacheco-Torres, R., \& Casillas, J. (2017). Energy consumption modeling by machine learning from daily activity metering in a hospital. Proceedings of the 22nd IEEE International Conference on Emerging Technologies and Factory Automation. doi:10.1109/ETFA.2017.8247667

Safdar, S., Khan, S. A., \& Shaukat, A. (2019). Customer experience management (CEM) for automation, data collection and methodology. Proceedings of the ICTC 2019. doi:10.1109/ICTC46691.2019.8939860

Sahni, P., Arora, G., \& Dubey, A. K. (2017). Healthcare waste management and application through big data analytics. Proceedings of the REDSET 2017.

Sahoo, P. K., Mohapatra, S. K., \& Wu, S.-L. (2017). Analyzing healthcare big data with prediction for future health condition. IEEE Access: Practical Innovations, Open Solutions, 4, 9786-9799. doi:10.1109/ ACCESS.2016.2647619

Sangiwe, M., Doan, T. N., Yun, J. A., \& Tshuma, N. (2018). Application of machine learning models in predicting length of stay among healthcare workers in underserved communities in South Africa. Human Resources for Health, 16(68), 1-9. doi:10.1186/s12960-018-0329-1 PMID:29301559

Scheinker, D., \& Brandeau, M. L. (2017). Analytical approaches to operating room management. In Health care systems engineering (pp. 17-26). Springer International Publishing. doi:10.1007/978-3-319-66146-9_2

Shamayleh, A., Awad, M., \& Farhat, J. (2020). IoT based predictive maintenance management of medical equipment. Journal of Medical Systems, 42(72), 1-12. doi:10.1007/s10916-020-1534- 8 PMID:32078712

Shams, I., Ajoriou, S., \& Yang, K. (2015). A predictive analytics approach to reducing 30-day avoidable readmissions among patients with heart failure, acute myocardial infarction, pneumonia, or copd. Health Care Management Science, 18(1), 19-34. doi:10.1007/s10729-014-9278-y PMID:24792081 
Shi, M., Jiang, R., Hu, X., \& Shang, J. (2019). A privacy protection method for health care big data management based on risk access control. Health Care Management Science, 1-16. doi:10.1007/s10729-019-09490-4 PMID:31338637

Silva, C., Oliveira, D., Peixoto, H., Machado, J., \& Abelha, A. (2018). Data mining for prediction of length of stay of cardiovascular accident inpatients. Proceedings of the DTGS. doi:10.1007/978-3-030-02843-5_43

Silvestri, S., Esposito, A., Garguilo, F., Sicuranza, M., Ciampi, M., \& De Pietro, G. (2019). A big data architecture for the extraction and analysis of ehr data. Proceedings of the 2019 IEEE World Congress on Services. doi:10.1109/ SERVICES.2019.00082

Simsek, S., Tiahrt, T., \& Dag, A. (2020). Stratifying no-show patients into multiple risk groups via a holistic data analytics-based framework. Decision Support Systems, 1-11. doi:10.1016/j.dss.2020.113269

Solangi, Z. A., Abd. Aziz, M. S., \& Asadullah. (2015). The study of internet of things (iot)-based healthcare acceptance in Pakistan. Proceedings of the IEEE International Conference on Engineering Technologies and Social Science.

Sousa, M. J., Pesqueira, A. M., Lemos, C., Sousa, M., \& Rocha, A. (2019). Decision-making based on big data analytics for people management in healthcare organizations. Journal of Medical Systems, 43(290), 1-10. doi:10.1007/s10916-019-1419-x PMID:31332535

Stadler, J. G., Donlon, K., Siewert, J. D., Franken, T., \& Lewis, N. E. (2016). Improving the efficiency and ease of healthcare analysis through use of data visualization dashboards. Big Data, 4(2), 129-135. doi:10.1089/ big.2015.0059 PMID:27441717

Stephens, E. (2018). Patient-centered analytics. OR-MS Today, 45(6). Advance online publication. doi:10.1287/ orms.2018.06.09

Stopa, B. M., Robertson, F. C., Karhade, A. V., Chua, M., Broekman, M. L. D., Schwab, J. H., Smith, T. R., \& Gormley, W. B. (2019). Predicting nonroutine discharge after elective spine surgery: External validation of machine learning algorithms. Journal of Neurosurgery. Spine, 31(5), 742-747. doi:10.3171/2019.5.SPINE1987 PMID:31349223

Sudarto, F., Kristiadi, D. P., Warnars, H. L. H. S., Ricky, M. Y., \& Hashimoto, K. (2018). Developing of Indonesian intelligent e-health model. Proceedings of the 1st 2018 INAPR International Conference.

Sumarsono, A. M., \& Almunawar, M. N. (2019). Big data in healthcare for personalization \& customization of healthcare services. Proceedings of the 2019 International Conference on Information Management and Technology (ICIMTech). doi:10.1109/ICIMTech.2019.8843822

Tan, C. S., Deng, X., Tai, E. S., Khoo, Y. H. E., Toh, E. S., Salloway, M. K., . . Wee, H. L. (2016). Predicting high cost patients with type 2 diabetes mellitus using hospital databases in a multi-ethnic Asian population. Proceedings of the IEEE-EMBS International Conference on Biomedical and Health Informatics.

Tang, W., Ren, J., Deng, K., \& Zhang, Y. (2019). Secure data aggregation of lightweight e- healthcare iot devices with fair incentives. IEEE Internet of Things Journal, 6(5), 8714-8726. doi:10.1109/JIOT.2019.2923261

Tesfaye, B., Atique, S., Azim, T., \& Kebede, M. M. (2019). Predicting skilled delivery service use in Ethiopia: Dual application of logistic regression and machine learning algorithms. BMC Medical Informatics and Decision Making, 19(209), 1-10. doi:10.1186/s12911-019-0942-5 PMID:31690306

Thangaraj, M., Ponmalar, P. P., \& Anuradha, S. (2015). Internet of things (iot) enabled smart autonomous hospital management system-a real world health care use case with the technology drivers. Proceedings of the IEEE International Conference on Computational Intelligence and Computing Research. doi:10.1109/ ICCIC.2015.7435678

Tideman, S., Santillana, M., Bickel, J., \& Reis, B. (2019). Internet search query data improve forecasts of daily emergency department volume. Journal of the American Medical Informatics Association, 26(12), 1574-1583. doi:10.1093/jamia/ocz154 PMID:31730701

Turgeman, L., May, J. H., \& Scuilli, R. (2017). Insights from a machine learning model for predicting the hospital length of stay (LoS) at the time of admission. Expert Systems with Applications, 78, 376-385. doi:10.1016/j. eswa.2017.02.023 
Ukil, A., Bandyoapdhyay, S., Puri, C., \& Pal, A. (2016). IoT healthcare analytics: The importance of anomaly detection. Proceedings of the 2016 IEEE 30 the International Conference on Advanced Networking and Applications. doi:10.1109/AINA.2016.158

Uma, M. S., \& Thanayaki, C. V. (2020). Secure medical health care content protection system (SMCPS) with watermark detection for multi cloud computing environment. Multimedia Tools and Applications, 79(5-6), 4075-4097. doi:10.1007/s11042-019-7724-Z

Van Wilder, A., Spriet, I., Van Eldere, J., Peetermans, W. E., Vanhaecht, K., Vandersmissen, J., Artois, M., Gilis, K., Vanautgaerden, P., Balcaen, K., Rademakers, F. E., \& Bruyneel, L. (2020). Translating data from an electronic prescribing and medicines administration system into knowledge. Medical Care, 58(1), 83-89. doi:10.1097/MLR.0000000000001222 PMID:31584461

Vargheese, R., \& Viniotis, Y. (2014). Influencing data availability in iot enabled cloud based e- health in a 30 day readmission context. Proceedings of the 10th IEEE International Conference on Collaborative Computing: Networking, Applications and Worksharing. doi:10.4108/icst.collaboratecom.2014.257621

Verma, N., Xavier, T., \& Agrawal, D. (2016). Biometric attendance and big data analysis for optimizing work processes. Proceedings of the Nursing Informatics 2016.

Weng, W.-H., Wagholikar, K. B., McCray, A. T., Szolovits, P., \& Chueh, H. C. (2017). Medical subdomain classifications of clinical notes using a machine learning-based natural language processing approach. $B M C$ Medical Informatics and Decision Making, 17(155), 1-13. doi:10.1186/s12911-017-0556-8 PMID:29191207

Wills, M. J. (2014). Decisions through data: Analytics in healthcare. Journal of Healthcare Management, 59(4), 254-262. doi:10.1097/00115514-201407000-00005 PMID:25154123

Wojtusiak, J., Elashkar, E., \& Nia, R. M. (2018). C-lace2: Computational risk assessment tool for 30-day post hospital discharge mortality. Health and Technology, 8(5), 341-351. Advance online publication. doi:10.1007/ s12553-018-0263-1

Wolf, H., Herrmann, K., \& Rothermel, K. (2013). Dealing with uncertainty: Robust workflow navigation in the healthcare domain. ACM Transactions on Intelligent Systems and Technology, 4(4), 65. doi:10.1145/2508037.2508046

Woodbridge, D. M.-k., Wilson, A. T., Rintoul, M. D., \& Goldstein, R. H. (2015). Time series discord detection in medical data using a parallel relational database. Proceedings of the 2015 IEEE International Conference on Bioinformatics and Biomedicine (BIBM). doi:10.1109/BIBM.2015.7359885

Woodside, J. M. (2014). Virtual health management. Proceedings of the 2014 11th International Conference on Information Technology: New Generations.

Xu, E., Mei, J., Li, J., Yu, Y., Huang, S., \& Qin, Y. (2019). From EHR data to medication adherence assessment: a case study on type 2 diabetes. Proceedings of the IEEE International Conference on Healthcare Informatics. doi:10.1109/ICHI.2019.8904786

Xu, H., Wu, W., Nemati, S., \& Zha, H. (2017). Patient flow prediction via discriminative learning of mutuallycorrecting processes. IEEE Transactions on Knowledge and Data Engineering, 29(1), 157-171. doi:10.1109/ TKDE.2016.2618925

Xu, J., Xue, K., Li, S., Tian, H., Hong, J., Hong, P., \& Yu, N. (2019a). Healthchain: A blockchain-based privacy preserving scheme for large-scale health data. IEEE Internet of Things Journal, 6(5), 8770-8781. doi:10.1109/ JIOT.2019.2923525

Yamashita, Y., Iwasaki, H., Muroi, Y., Hida, M., \& Shigemi, H. (2019). Development of in- hospital infection management using iot. Proceedings of the MEDINFO 2019: Health and Wellbeing e-Networks for All.

Yang, L., Yao, T., Liu, G., Sun, L., Yang, N., Zhang, S., \& Hou, X. et al. (2019). Monitoring and control of medical air disinfection parameters of nosocomial infection system based on internet of things. Journal of Medical Systems, 43(126), 1-7. doi:10.1007/s10916-019-1205-9 PMID:30919075

Ye, B., Basdekis, I., Smyrlis, M., Spanoudakis, G., \& Koloutsou, K. (2018). A big data repository and architecture for managing hearing loss related data. Proceedings of the 2018 IEEE EMBS International Conference on Biomedical \& Health Informatics. doi:10.1109/BHI.2018.8333397 
Ye, Y., Zhao, Y., Shang, J., \& Zhang, L. (2019). A hybrid it framework for identifying high- quality physicians using big data analytics. International Journal of Information Management, 47, 65-75. doi:10.1016/j. ijinfomgt.2019.01.005

Yip, K., Pang, S.-K., Chan, K.-T., Chan, C.-K., \& Lee, T.-L. (2016). Improving outpatient phlebotomy service efficiency and patient experience using discrete-event simulation. International Journal of Health Care Quality Assurance, 29(7), 733-743. doi:10.1108/IJHCQA-08-2015-0093 PMID:27477930

Yoon-Su, J., \& Seung-Soo, S. (2019). Staganography-based healthcare model for safe handling of multimedia health care information using vr. Multimedia Tools and Applications, 1-15. doi:10.1007/s11042-019-07833-5

Zachariadis, C., Velivassaki, T. H., Zahariadis, T., Railis, K., \& Leligou, H. C. (2018). Matisse: A smart hospital ecosystem. Proceedings of the 2018 21st Euromicro Conference on Digital System Design.

Zampieri, F. G., Salluh, J. I. F., Azevedo, L. C. P., Kahn, J. M., Damiani, L. P., Borges, L. P., Viana, W. N., Costa, R., Corrêa, T. D., Araya, D. E. S., Maia, M. O., Ferez, M. A., Carvalho, A. G. R., Knibel, M. F., Melo, U. O., Santino, M. S., Lisboa, T., Caser, E. B., Besen, B. A. M. P., \& Soares, M. et al. (2019). ICU staffing feature phenotypes and their relationship with patients' outcomes: An unsupervised machine learning analysis. Intensive Care Medicine, 45(11), 1599-1607. doi:10.1007/s00134-019-05790-z PMID:31595349

Zhang, H., Li, J., Wen, B., Xun, Y., \& Liu, J. (2018). Connecting intelligent things in smart hospitals using nbiot. IEEE Internet of Things Journal, 5(3), 1550-1560. doi:10.1109/JIOT.2018.2792423

Zhang, Y. (2019). Patient-specific readmission prediction and intervention for health care. International Journal of Prognostics and Health Management, 10, 1-5.

Zhang, Y., Qiu, M., Tsai, C.-W., Mehedi, M., \& Alamri, A. (2017). Health-cps: Healthcare cyber-physical system assisted by cloud and big data. IEEE Systems Journal, 11(1), 88-95. doi:10.1109/JSYST.2015.2460747

Zhu, H., \& Hou, M. (2018). Research on an electronic medical record system based on the internet. Proceedings of the 2018 2nd International Conference on Data Science and Business Analytics. doi:10.1109/ICDSBA.2018.00106

Zhu, Q., Akkati, A., \& Hongwattanakul, P. (2016). Risk feature assessment of readmission for diabetes. Proceedings of the 2016 IEEE International Conference on Bioinformatics and Biomedicine (BIBM). 